Portland State University

PDXScholar

Winter 3-5-2013

\title{
Hypothetical Would-Clauses in Korean EFL \\ Textbooks: An Analysis Based on a Corpus Study and Focus on Form Approach
}

Soyung Yoo

Portland State University

Follow this and additional works at: https://pdxscholar.library.pdx.edu/open_access_etds

Part of the Bilingual, Multilingual, and Multicultural Education Commons, and the International and Comparative Education Commons

Let us know how access to this document benefits you.

\section{Recommended Citation}

Yoo, Soyung, "Hypothetical Would-Clauses in Korean EFL Textbooks: An Analysis Based on a Corpus Study and Focus on Form Approach" (2013). Dissertations and Theses. Paper 911.

https://doi.org/10.15760/etd.911

This Thesis is brought to you for free and open access. It has been accepted for inclusion in Dissertations and Theses by an authorized administrator of PDXScholar. Please contact us if we can make this document more accessible: pdxscholar@pdx.edu. 
Hypothetical Would-Clauses in Korean EFL Textbooks:

An Analysis Based on a Corpus Study and Focus on Form Approach

by

Soyung Yoo

A thesis submitted in partial fulfillment of the requirements for the degree of

Master of Arts

in

Teaching English to Speakers of Other Languages

Thesis Committee:

John Hellermann, Chair

Susan Conrad

Gwen Heller Tuason

Portland State University

2013 
C2013 Soyung Yoo 


\begin{abstract}
This study analyzed hypothetical would-clauses presented in Korean high school English textbooks from two perspectives: real language use and Focus on Form approach. Initiated by an interest in the results of a corpus study, this study discussed hypothetical would-clauses in terms of how their descriptions in Korean EFL textbooks matched real language use. This study additionally investigated whether the textbooks presented the target language features in ways recommended by the Focus on Form approach.
\end{abstract}

In the past few decades, authentic language use and the Focus on Form approach have received a great amount of attention in the SLA field. Recognizing the trend in SLA as well as necessities in Korean EFL education, the Korean government has incorporated these two into the current $7^{\text {th }}$ curriculum. Such condition provided the momentum for the evaluation of the textbooks in these respects.

The findings show that the language features were hardly supplemented by the information drawn from real language data. In addition, there were very few attempts to draw learner attention to language forms while keeping them focused on communication as recommended by Focus on Form approach.

With increasing use of the English language, it is becoming more necessary for Korean EFL learners to use English in real life contexts where understanding correct nuances and delivering appropriate expressions may be important. Also, in EFL contexts like Korea, the students may have limited access to the target language input and little opportunities to produce outputs in extracurricular settings, so the integrated methodology of Focus on Form approach, rather than just using either one of structurecentered or meaning-oriented approach, would be of greater benefit to the students. 
However, the results strongly indicate that the textbooks neither incorporate the language features as they occur in naturally occurring language nor present them as to facilitate the learning of both form and meaning.

This study suggests that greater use of real language data and more thorough application of Focus on Form methods in the textbook writing process should be seriously considered. Thus, this study could be useful for curriculum developers and textbook writers in creating curriculum and language materials concerning the incorporation of grammar patterns based on actual language use as well as in improving textbooks with respect to the Focus on Form approach. 


\section{Acknowledgements}

Foremost, I would like to express my sincere gratitude to my advisor, Dr.

Hellermann, for his patience, encouragement, and immensely insightful advice

throughout this long process. Without his helpful guidance, I could not have completed this study.

I also would like to thank Dr. Conrad and Ms. Tuason for gladly agreeing to be second readers and giving me helpful comments.

Finally, I want to thank my son, Jeehun, for giving me emotional support during my difficult days, and my parents and husband in Korea who have continuously encouraged my efforts. 


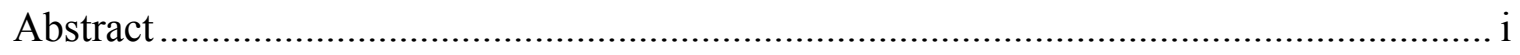

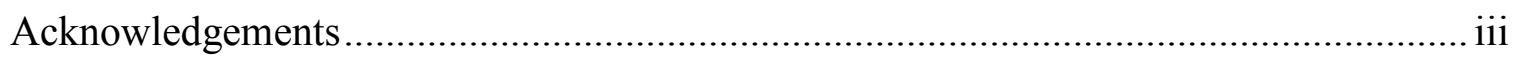

List of Tables .................................................................................................. viii

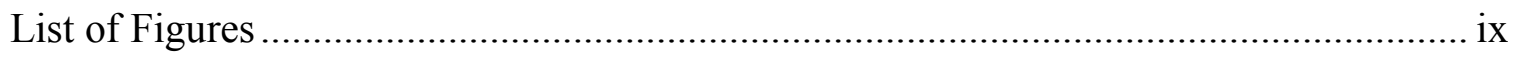

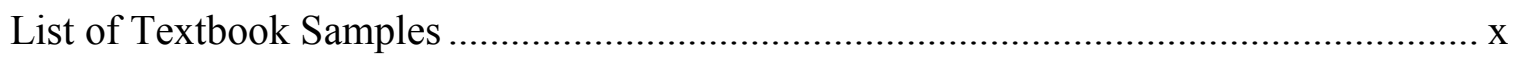

Chapter 1: Rationale and Purposes of the Study...................................................... 1

Chapter 2: Literature Review................................................................................... 3

2.1 The Korean $7^{\text {th }}$ National Curriculum for English Education and Major Amendments

2.2 Authentic Language Use: Grammar Writing in Textbook Writing and Real

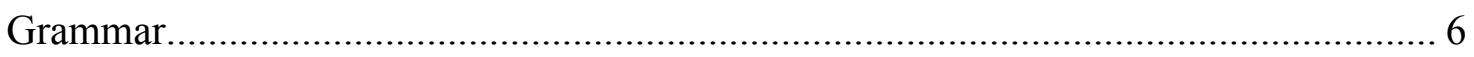

2.3. What Frazier's Findings Show and Imply................................................... 8

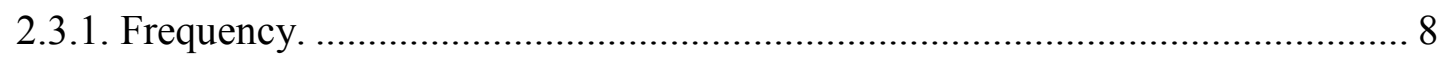

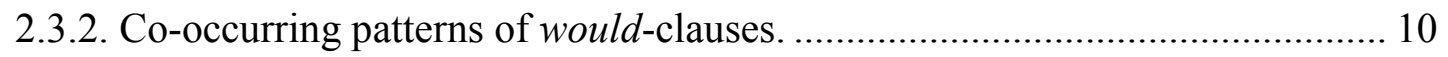

2.3.2.1. Alternative conditionals (Grammatical co-text)................................... 10

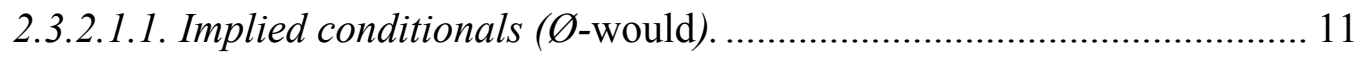

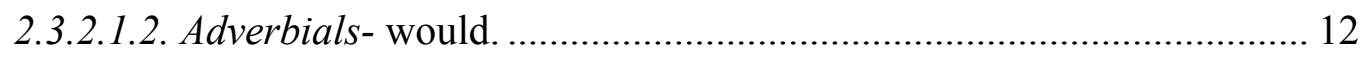

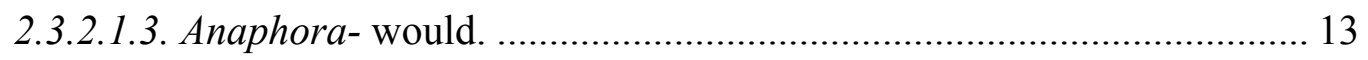

2.3.2.1.4. Generic noun phrases (indefinite article + noun)- would. ............... 14 
HYPOTHETICAL WOULD-CLAUSES IN KOREAN ENGLISH TEXTBOOKS V

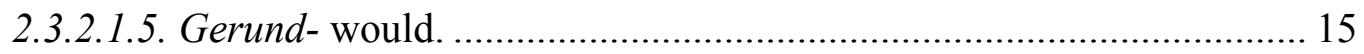

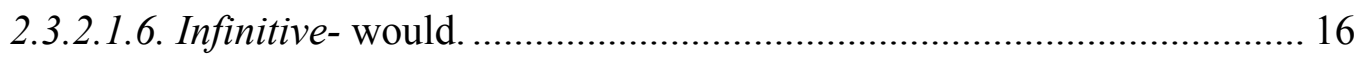

2.3.2.2. No-overt conditionals (lexico-grammar)............................................ 18

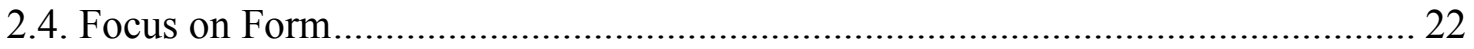

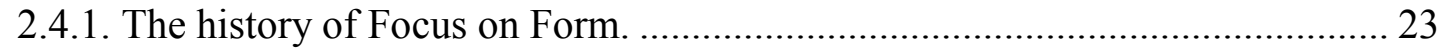

2.4.2. Application of Focus on Form: From implicit learning to explicit instruction.

2.4.3. The importance of output Focus on Form.

2.4.4. Direct approach: Application of Focus on Form to a range of linguistic levels.

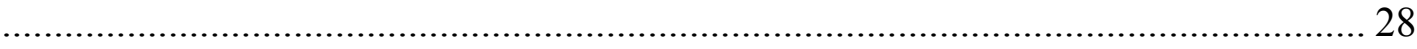

2.5. The Summary of Literature Review ..................................................................... 29

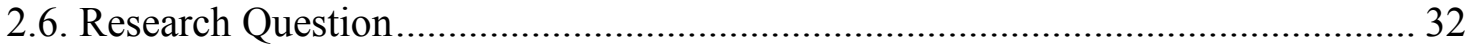

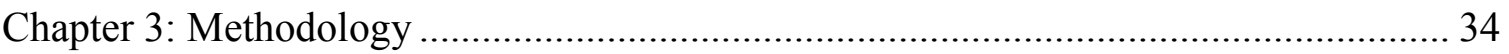

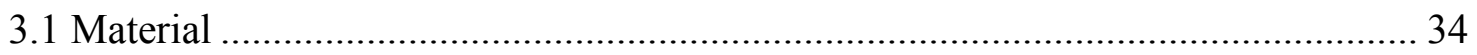

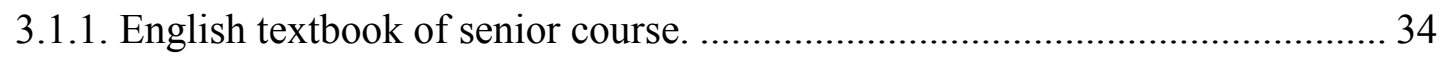

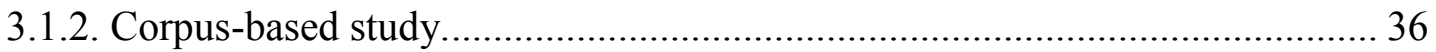

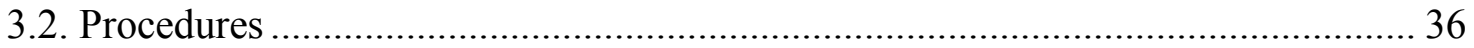

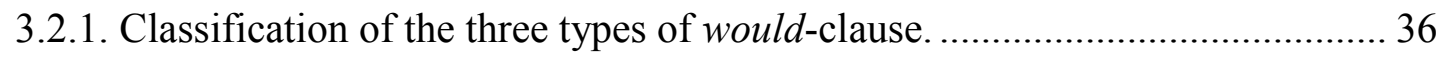

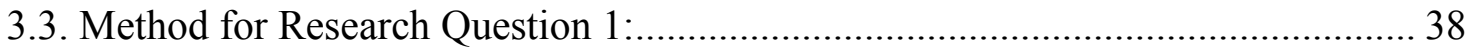

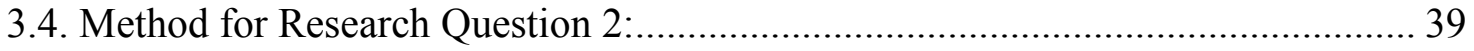


HYPOTHETICAL WOULD-CLAUSES IN KOREAN ENGLISH TEXTBOOKS vi

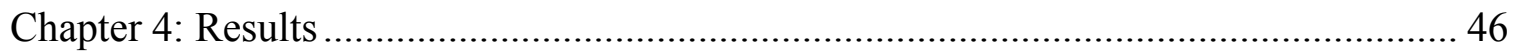

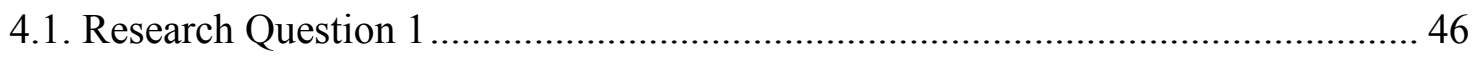

4.1.1. Real use of conditionals- frequency comparison:..................................... 46

4.1.2. Real use of conditionals- grammar patterns: ......................................... 49

4.1.2.1. Alternative conditionals (grammatical co-text).................................... 49

4.1.2.2. No-overt conditionals (lexico-grammar) ........................................... 52

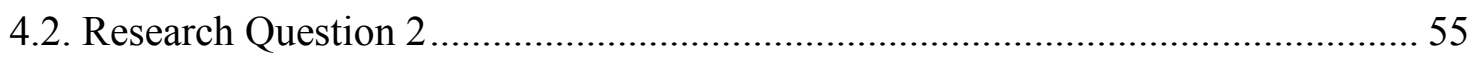

4.2.1. Focus on Form techniques used for would-clause conditionals. ..................... 55

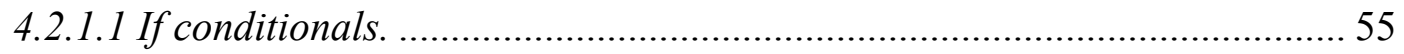

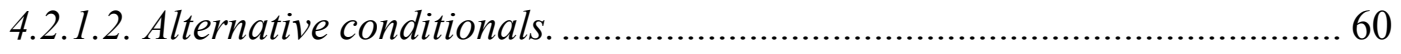

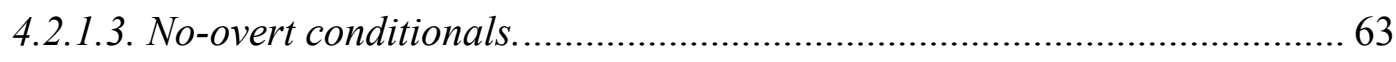

4.2.2. Comparison between CR tasks and exercises......................................... 65

4.2.3. Survey of activities used for hypothetical would-clauses.............................. 66

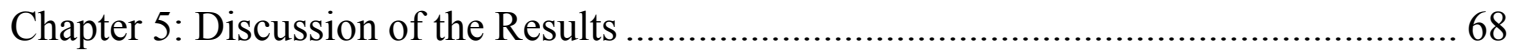

5.1. Real Language Use: Frequency Comparison of would-Clause Varieties ............. 68

5.2. Real Language Use: Grammar Patterns of Alternative Conditionals ................... 68

5.3. Real Language Use: Grammar Patterns of No-overt Conditionals ...................... 72

5.4. Focus on Form: Implicit vs. Explicit Method \& No Presence of Output-oriented

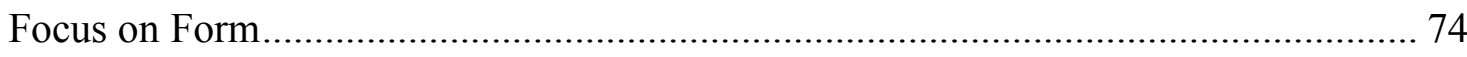


HYPOTHETICAL WOULD-CLAUSES IN KOREAN ENGLISH TEXTBOOKS vii

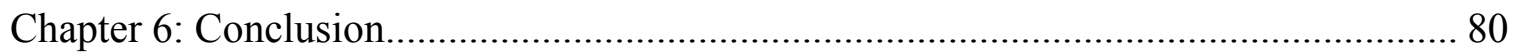

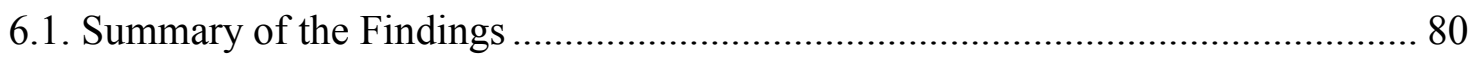

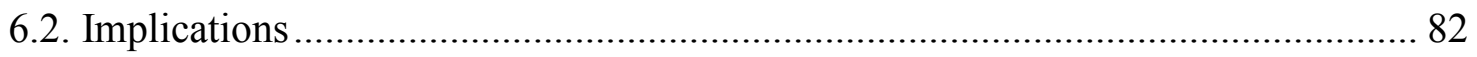

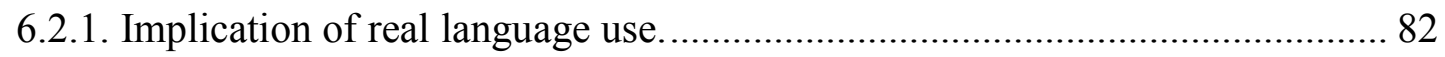

6.2.2. Implication of teaching approach (Focus on Form) .................................. 85

6.2.2.1. Application for input based Focus on Form (implicit to explicit). ............86

6.2.2.2. Application for output activity: integration of form and meaning focus. . 89

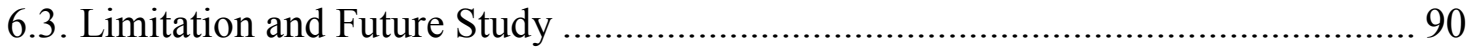

Appendix A Supplementary Activity 1: Consciousness raising task............................. 97

Appendix B Supplementary Activity 2: Dictogloss................................................ 100 
HYPOTHETICAL WOULD-CLAUSES IN KOREAN ENGLISH TEXTBOOKS viii

\section{List of Tables}

Table 1. The Types of would-clauses by Conditional Category ....................................

Table 2. Summary of Corpus Findings about Two Types of would-Clauses ................30

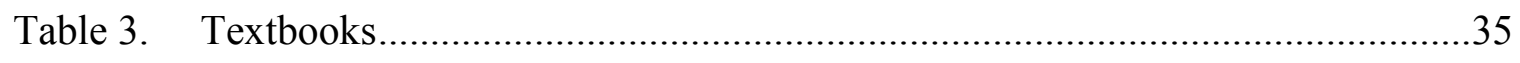

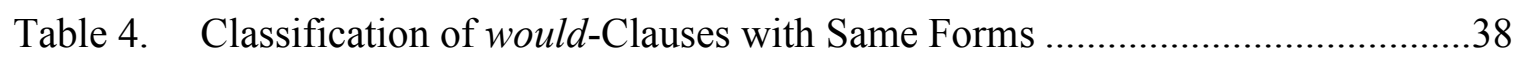

Table 5. Occurrence of the Tokens of Would-Clauses in KE Textbooks.....................47

Table 6. Would- Clauses by Conditional Category in Frazier's Corpus Study.............47

Table 7. Co-text Pattern and Function of Alternative Conditionals ..............................50

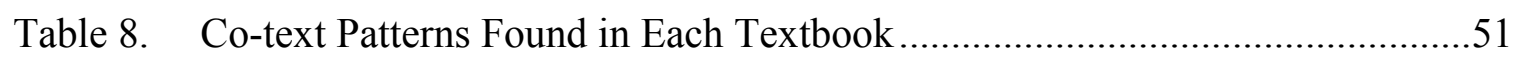

Table 9. Lexico-Grammar Pattern of No-overt Conditionals .....................................53

Table 10. Lexico-Grammar Patterns of No-overt Conditionals Found in Each

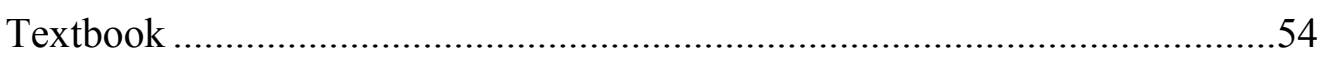

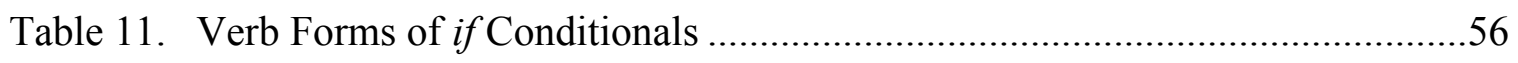

Table 12. Focus on Form Techniques Found in if Conditionals ..................................57

Table 13. Phrase and Verb Forms of Alternative Conditionals ..................................60

Table 14. Focus on Form Techniques Found in Alternative Conditionals .....................61

Table 15. Verb Form of No-overt Conditionals.....................................................64

Table 16. Focus on Form Techniques Found in No-overt Conditionals........................64

Table 17. Textbook Exercises and CR Tasks ........................................................66 
HYPOTHETICAL WOULD-CLAUSES IN KOREAN ENGLISH TEXTBOOKS ix

\section{List of Figures}

Figure 1. Implicit-Explicit Continuum of Focus on Form Techniques .......................25

Figure 2. Focus on Form Techniques/Tasks Based on Explicitness and Output

Mode

Figure 3. The Four Focus on Form Techniques Found in the Textbooks

Figure 4. The Comparison of Frequency between Corpus Findings and Korean EFL

Textbooks.

Figure 5. The Varieties of Grammatical Co-text Pattern Found in the Five

Textbooks...

Figure 6. The Frequency of if Conditionals Categorized by Focus on Form

Techniques

Figure 7. The Frequency of the Co-text Patterns Categorized by the Focus on Form

Technique 


\section{List of Textbook Samples}

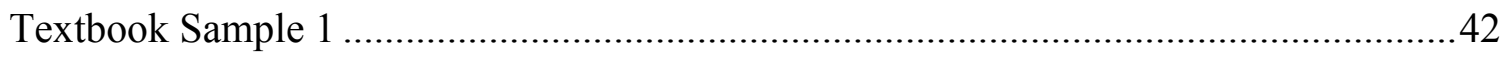

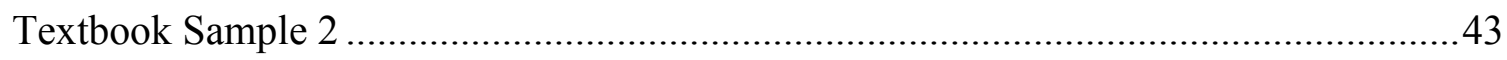

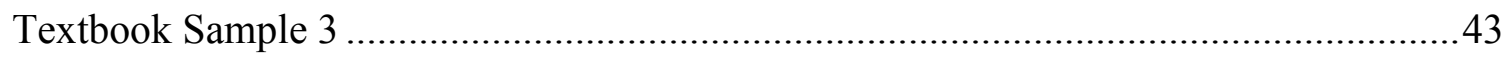

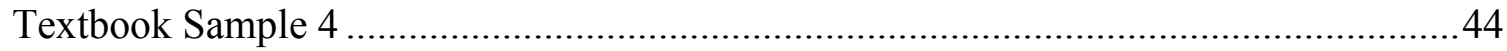

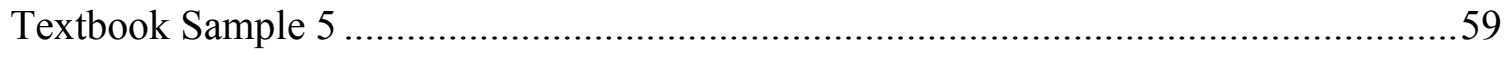

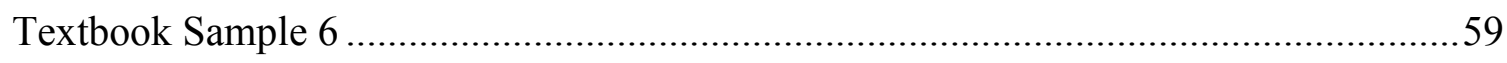

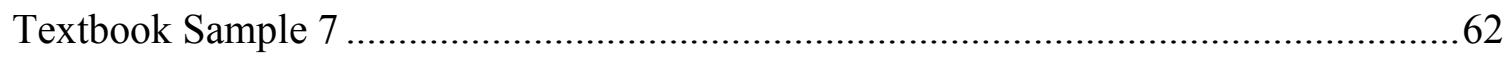

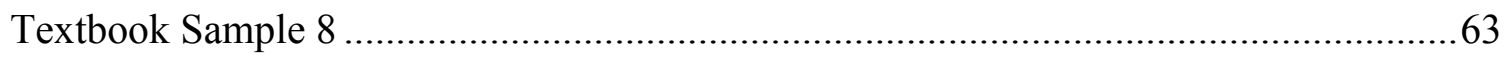

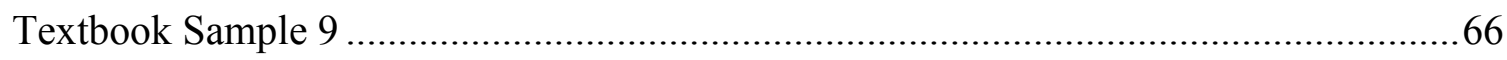

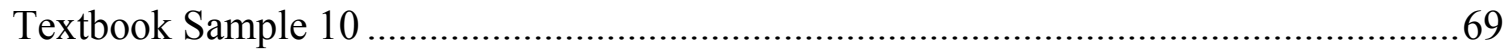

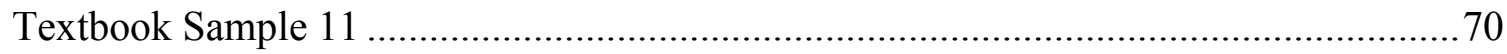

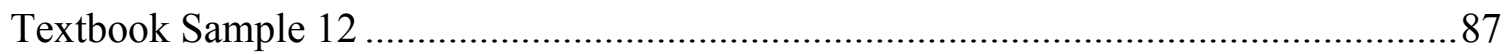




\section{Chapter 1: Rationale and Purposes of the Study}

This study was initiated by the interest in hypothetical would-clause patterns found in a corpus-based study. According to my personal experience, hypothetical wouldclauses were always taught as consequences of if-conditions in Korean EFL classes. However, Frazier's corpus study (2003) led me to rethink the co-text of if-conditions and would-clauses, which were regarded as typical hypothetical structures in existing research literature and English learning materials. His study indicates that hypothetical wouldclauses often occur without any corresponding if-conditions. In other words, in naturally occurring language, hypothetical /counterfactual conditions are either marked by grammatical structures other than if-conditions or implied in the context. In addition to these findings, Frazier notes the considerable occurrence of another type of would-clauses without if-conditions. These would-clauses carry epistemic meaning and do not have overt structures that convey conditionality. ${ }^{1}$

These findings contradict the if-clause-centered instruction of hypothetical conditionals and polite formulaic expression-focused teaching of would-clauses that I can recall from 25 years ago. Such a difference caused me to develop an academic curiosity about how hypothetical would-clauses, especially commonly used features that were not thoroughly evaluated in previous English learning contexts (i.e., alternative conditionals and no-overt conditionals), are applied to the current English language curriculum in Korea. As such, I investigated Korean school English textbooks to explore whether

\footnotetext{
${ }^{1}$ In Frazier's study, would-clauses without overt conditionals have epistemic meaning because he excludes all tokens carrying polite volitional meaning.
} 
textbooks incorporate hypothetical would-clauses as they appear in naturally occurring language.

Additionally, I wanted to examine the way in which these features are presented in the textbooks because instructional method is critical for facilitating learning of the features. Korean school English textbooks, which were selected for the analysis, are instructional materials officially approved by the Korean government. Thus they follow the same guidelines issued by the Korean Ministry of Education. The current $7^{\text {th }}$ national curriculum has an ultimate goal of cultivating communicative competence and suggests Focus on Form as an appropriate approach to meet this goal. A Focus on Form approach attempts to draw students' attention to form but is not isolated from communication, placing emphasis on both form and meaning. In hypothetical would-clauses, conditionals are realized through a variety of forms and would-clauses vary in form (entail infinitive or perfect forms) depending on unreal meaning and time references, which makes drawing attention to the form necessary. It seems that form- focused instruction for communication is critical, especially in EFL environments that lack exposure to naturally occurring input. For these reasons, I examined the degree to which textbooks explicitly focused on forms of the target language features while providing them in a context of communicative activity.

The results of the examination led to a discussion of the possible implications for textbook writing of the target language features regarding the incorporation of grammar patterns based on actual language use as well as suggestions for improvement on aspects of Focus on Form approach. 


\section{Chapter 2: Literature Review}

The literature review has three parts. The first section briefly surveys the current Korean national curriculum of English education and two amendments implemented by the Korean Ministry of Education, Science, and Technology (MEST). These amendments were incorporated into the curriculum to align the Korean EFL educational field with language teaching approaches currently being studied and advocated by SLA research. The next two sections review the two theoretical backgrounds for this study that are relevant to the amendments: a corpus study in terms of what it shows about the grammar form of the target language features from natural language use and Focus on Form as an approach for incorporating grammar into textbook writing and grammar instruction.

\subsection{The Korean $7^{\text {th }}$ National Curriculum for English Education and Major Amendments}

This part surveys the goals and items of the current $7^{\text {th }}$ Korean national curriculum for English education and explains how they are related to the present study. The primary goal of the $7^{\text {th }}$ National English Curriculum, enacted in 2001, is to cultivate the communicative competence of English, the global language of the information age. As it can been seen from the Sixth Korean English Curriculum, which adopted a communicative curriculum instead of the previous grammar-centered curricula, developing communicative competence has been a fundamental issue of English education policy in Korea. To help achieve that goal, various amendments have been made to the current curriculum. The two most noticeable changes relevant to the present study were the authentic language use amendment of 2006 and the Focus on Form approach amendment of 2007. 
An innovative agenda added to the English language curriculum in 2006 was bringing real communicative situations to language classrooms by using authentic language. Kennedy (1998) asserts that corpus study can directly contribute to language curriculum by providing important information for selecting which teaching content to prioritize. In line with that finding, the Korean Ministry of Education stated that vocabulary selection should be based on empirical data, such as a corpus, rather than using arbitrary decision-making processes as in the past. Accordingly, the current Korean curriculum provides a list of vocabulary based on frequency information from analyses of a variety of corpus data (ANC (American National Corpus), BNC (British National Corpus), BC (Brown Corpus)).

Although the Korean policy does not directly dictate the application of naturally occurring language with respect to grammar writing, the 'authentic language use' suggested by the 2006 policy implies the inclusion of grammar structures as well as vocabulary lists. A preface of one of the textbooks to be examined in this study states that it aims to introduce language that is commonly used in real life contexts in every chapter (Geumseong Publishing).

While the aforementioned 2006 agenda prescribed a direction for the process of language feature selection in the English curriculum, 2007 reform suggested an instructional method that aims to optimize the learning process of the features. Introduced in the sixth curriculum (1995-2000), communicative language teaching 
HYPOTHETICAL WOULD-CLAUSES IN KOREAN ENGLISH TEXTBOOKS

$(\mathrm{CLT})^{2}$ has been a major approach for English language education in Korea since and is also included in the seventh curriculum. However, the 2007 reform adopted a new teaching method, Focus on Form, with the purpose of implementing balanced development of fluency with grammatical accuracy. The following is the Korean Ministry of Education, Science, and Technology's rationale for adding the new approach.

[The rationale behind the proposal of the amendment] was the understanding that if English education limits itself by focusing too much on communicative function and the function's examples in the text, as in the Sixth Curriculum, students will have limited English ability due to the lack of grammatical knowledge; it was also understood that in an EFL environment with inadequate language input like Korea, such English education is unlikely to satisfy both fluency and accuracy (Notification NO. 2007-79 of MEST, original text in Korean, translated by Soyung Yoo).

As such, this amendment was issued with the purpose of implementing the most effective way of grammar teaching within the basic frame of a communication-centered curriculum. The reform is distinguished from both the traditional grammar teaching of the first through fifth curricula and the over-adherence to communicative teaching in the sixth and pre-reform seventh curricula. The amendment includes a list of thirty six English language forms and the definition of Focus on Form, "to guide the learners to build their own hypothesis on the given grammar structures through noticing and

\footnotetext{
${ }^{2}$ CLT focuses on the ability to execute one's communicative needs and accordingly, places emphasis on fluency over accuracy.
} 
attention" (p. 27). To respond to the necessity of providing grammar instruction while also enhancing communicative competence, the 2007 amendment incorporates Focus on Form into the reformed curriculum to pursue a more balanced development of fluency and accuracy.

I briefly surveyed two agendas included in the current Korean English curriculum since the issues in these agendas are the theoretical and methodological backgrounds of the present study. In the following two sections, I looked into these two issues in terms of incorporating the target grammar features in grammar instruction and textbook writing.

\subsection{Authentic Language Use: Grammar Writing in Textbook Writing and Real Grammar}

For the last few decades, corpus linguistics has made a number of contributions to language education by introducing large, principled collections of authentic language that can be analyzed with computer assisted techniques. It has suggested new methods of teaching and learning such as classroom concordancing. Accordingly, many corpus studies have focused on the use of concordance programs as classrooms activities in which students analyze real language data to gain more insight toward language use by themselves (e.g. Johns, 1991; Gavioli, 2001; Zorzi, 2001; O’Keeffe \& Farr, 2003; Shin \& Nation, 2008, etc.).

In addition, corpus linguistics can also give insight into textbook writing by providing empirically validated data about particular grammatical features. Such data "may not be accessible to native speaker intuition" (Hunston, 2005, p. 31) and characterizes certain language features as they are used in natural contexts. Many empirical studies of English grammar have offered the information of various 
grammatical features used by language users with a continuing interest in incorporating real grammar into language teaching(e.g. Mair, 1990; Hyland, 1994; Conrad, 1999, 2000, 2010; Biber et al, 2002; Frazier, 2003; Duffley, 2006; Barbieri and Eckhardt, 2007, etc.). Most of these studies indicate a discrepancy between ESL/EFL textbook descriptions of target grammars and the information from real language use, suggesting an inclusion of corpus-based grammar in language teaching and textbook writing. ${ }^{3}$

The present study is concerned with the issue of incorporating corpus findings of grammar into textbook writing, particularly, the grammatical structures of hypothetical would-clauses. By comparing textbook grammar descriptions with real life language use, this study explores the present state of grammar teaching in textbooks. Thus, I reviewed what the corpus findings show and imply with regards to real life language use. The corpus findings used in this study were taken from Frazier's 2003 study on hypothetical/counterfactual would-clauses, which contains the results of analyses of data retrieved from the following corpora:

1) Approximately $1,014,000$-word Brown corpus for written data

\footnotetext{
${ }^{3}$ For example, Biber and Reppen (2002)'s study shows how a corpus can provide reliable information for grammar writing with respect to actual language use. They discuss serious discrepancies between actual language uses and widely-held intuition about language use while comparing information presented in popular ESL/EFL grammar materials and information of real language use based on corpus studies. For instance, progressive aspect verb phrases are often prominently presented in dialogue parts of ESL /EFL materials. Biber and Reppen suggest that this is due to a common misconception in textbook authors that progressive aspects are unmarked choices for conversation. Contrary to the belief of many textbook writers, frequency counts of corpora indicate that simple aspect verb phrases are 20 times as frequent as progressive aspect verb phrases. Their study shows that grammar writing relying on the authors' intuition can fail to provide accurate information about the language used by speakers and writers in real situations while corpus studies can contribute to grammar writing of authentic language through frequency information.
} 
HYPOTHETICAL WOULD-CLAUSES IN KOREAN ENGLISH TEXTBOOKS

2) Total 165,420-word sample of SBC (Santa Barbara Corpus of Spoken American English) and MICASE (Michigan Corpus of Academic Spoken English) for spoken data.

\subsection{What Frazier's Findings Show and Imply}

Frazier starts his article by introducing a cover story of a Newsweek magazine titled "What Would Jesus Do?" which dealt with a child-abuse scandal in the Catholic Church. He then questions if anybody who read this headline asked, "What would Jesus do if what?" His point here is that hypothetical conditions (i.e. if-clauses) are often contextually implied rather than explicitly stated when used with consequential wouldclauses. Subsequently, he argues that these usages are rarely covered in English language textbooks when considering their frequent occurrences in real-life contexts. With these issues in mind, Frazier reports his findings on how hypothetical would-clauses are used in naturally occurring language. His findings can be described in terms of the following three aspects: frequency (how common one feature is relative to another), patterns (particular associations of grammatical features), and register variations.

\subsubsection{Frequency.}

In Frazier's study, frequency information is especially worth noting since the findings are quite different from the description of the form in a popular grammar reference book (Quirk et al, 1985) in that "the most typical context in which hypothetical would/should occurs is in the presence of If" (p. 234). As seen in table 1, hypothetical would for the most part occurs without any corresponding if-clauses. 
Table 1.

Types of would-Clauses by Conditional Category (Based on Frazier (2003)'s Analysis)

\begin{tabular}{|c|c|c|c|c|c|c|}
\hline \multirow{2}{*}{\multicolumn{2}{|c|}{ Type of clauses }} & \multirow[t]{2}{*}{$\begin{array}{l}\text { Form of } \\
\text { conditions }\end{array}$} & \multirow[t]{2}{*}{ Example } & \multicolumn{3}{|c|}{$\begin{array}{c}\text { Register } \\
\text { (\%) }\end{array}$} \\
\hline & & & & $\mathbf{S}$ & $\mathbf{W}$ & $\overline{\mathbf{A}}$ \\
\hline \multicolumn{2}{|c|}{$\begin{array}{l}\text { Conditionals with if- } \\
\text { conditions }\end{array}$} & $\begin{array}{l}\text { If-conditions } \\
\text { adjoin the } \\
\text { corresponding } \\
\text { would-clauses }\end{array}$ & $\begin{array}{l}\text { It would be enough if } \\
\text { committees were to } \\
\text { meet }\end{array}$ & 26 & 24 & $\begin{array}{l}2 \\
5\end{array}$ \\
\hline \multirow[t]{2}{*}{$\begin{array}{l}\text { Conditionals } \\
\text { without if- } \\
\text { conditions }\end{array}$} & $\begin{array}{l}\text { Alternative } \\
\text { conditionals }\end{array}$ & $\begin{array}{l}\text { The condition is } \\
\text { marked by a } \\
\text { structure other } \\
\text { than if-clauses } \\
\text { (e.g. gerund, } \\
\text { infinitive etc.) }\end{array}$ & $\begin{array}{l}\text { Letting the } \\
\text { administration take } \\
\text { details off their hands } \\
\text { would give them more } \\
\text { time to inform } \\
\text { themselves about } \\
\text { education as a whole. }\end{array}$ & 49 & 69 & $\begin{array}{l}5 \\
9\end{array}$ \\
\hline & $\begin{array}{l}\text { No-overt } \\
\text { conditionals }\end{array}$ & $\begin{array}{l}\text { The absence of } \\
\text { any conditional } \\
\text { clause }\end{array}$ & $\begin{array}{l}\text { Are human beings still } \\
\text { evolving? It would } \\
\text { seem that evolution is } \\
\text { impossible now that } \\
\text { the ability to } \\
\text { reproduce is } \\
\text { essentially universally } \\
\text { available. }\end{array}$ & 23 & 6.9 & $\begin{array}{l}1 \\
5\end{array}$ \\
\hline
\end{tabular}

(S: spoken data, W: written data, A: average percentage of two data)

According to Frazier's study, would-clauses without if-conditions (no-overt and alternative conditionals) account for nearly three-quarters of the hypothetical wouldenvironments in the corpus. Alternative structure conditionals (e.g. gerunds - would cotext patterns) account for about $59 \%$ of the total. The other type, less common but still salient, is would-clauses without overt conditionals, occupying $15 \%$ of the total. These two types of would-clauses (74\%) outnumber would-clauses with if-conditions $(25 \%)$ by almost three times. Thus, the frequency information indicates that would-clauses without if-conditions occur quite often in real language use. 


\subsubsection{Co-occurring patterns of would-clauses.}

Another noticeable finding from Frazier's corpus data is that alternative conditionals and no-overt conditionals, which occupy a significant amount in real language, are associated with certain type of grammatical patterns: grammatical co-text and lexico-grammar.

\subsubsection{Alternative conditionals (Grammatical co-text).}

As previously mentioned, Frazier's corpus findings challenge the notion that ifwould co-occurring patterns are the most typical of its kind, especially with findings that other structures (e.g. gerunds, infinitives, etc.) are often used to substitute for if. Conrad (2010) refers to this type of pattern as grammatical co-text, defining it as when "a particular grammatical feature tends to occur with specific other grammatical features"(p.

5). The co-occurring grammatical features act as conditions and can be paraphrased into if-clauses. For instance, in the example of Getting your book published would entail finding an agent, one can paraphrase the gerund phrase with an if-condition without propositional meaning changes, such as If you want to get your book published, it would entail finding an agent. However, such structural substitution may create different pragmatic tones.

Van der Auwera (1986) presents if-less conditionals with and and or. He argues that imperative sentences with coordinate conjunctions may have conditional meanings. For example, Open the window and I'll kill you can be rewritten as if you open the window, I'll kill you. Haiman (1986) also associates coordinate conjunction, and, with the word if, illustrating that the use of the word and and the modern usage of if was derived from and in early Modern English. Frazier (2003) argues, citing Haiman, that omitting 
the word if in a conditional clause will raise the condition from subordinate to coordinate status (i.e. if you open the window $\rightarrow$ Open the window and...) and render the matrix and subordinate clauses paratactic, giving a different pragmatic value to the sentence. Frazier further develops this argument toward the nominalized form of alternative conditions (e.g. gerund constructions). The example above illustrates this, as nominalizing the condition and placing it at the subject position (getting your book published would..) shows a stronger position of the speaker/writer regarding the possibility of the condition compared to that in if-clause equivalent.

The change of tone created by structural substitution can be also seen in alternative conditions other than gerund structures. This will be further addressed with an introduction of six types of alternative conditionals: implied conditionals, adverbialwould, anaphora-would, generic noun-would, gerund-would, and infinitive-would.

\subsection{Implied conditionals (Ø-would).}

Implied conditionals refer to conditionals in which if-conditions are hidden but still implied in the contexts.

(1) TA: Um, alternatively, we could show crossing over okay? And what that would look like, is let's say, you had a, reciprocal exchange between, the A gene on, chromatids two and three okay? What that would look like, (( 0.6-sec pause while instructor writes)) would be something like this. Bs, were not involved so they stay the same (( 0.5 -sec pause while instructor writes $))$ and 
you should be able to follow this through and see, why you wouldn't get, all

parentals here. ${ }^{4}$ (Frazier, 2003, p. 460)

In this passage, conditional-clauses can be retrieved from the context. For example, if we show crossing over. Thus, phrases hidden in the context have a conditional function of triggering non-real or imaginary event. Implied conditionals may be used to avoid repetition if it was already presented in the context as shown above.

2.3.2.1.2. Adverbials- would.

Adverbials also are kinds of alternative conditions that occur with hypothetical would-clauses. The most common adverbials that mark conditions are ordinarily, without + [noun phrase], and ideally.

(2) Phil: [He's a] banker

Brad: [Yeah]

Phil: And he'd be good on one hand. [But],

Brad:

[Yeah].

Phil: I would like, ideally, I' $\underline{\mathrm{d}}$ want em both. (Frazier, SBC)

\footnotetext{
${ }^{4}$ Frazier argues that one uses would structures to index a description of an object that exists from a perspective displaced from its original reality. Because the TA cannot accurately represent the three-dimensional shape of a chromosome with a two-dimensional diagram on the board, he tries to put himself in an imaginary space and tries to show the object with physical reenactment rather than depicting it. As a result, the listener can experience an imaginary event through of the reenactment of the speaker. Frazier notes that these usages of would structures occur very frequently in spoken contexts such as lecture settings.
} 
In the last line, ideally can be substituted with if possible, which refers to a hypothetical condition that was not fulfilled. Excerpt (3), below, show an example with 'without':

(3) Without the good magazines, without their [the good magazines'] book reviews, their hospitality to European writers, without above all their awareness of literary standards, we might very well have a generation of Krim's heros-Wolfes, Farrells, Dreisers, and I might add, Sandburgs and Frosts and MacLeishes in verse- and then where would we be? (Frazier, Brown G)

In (3), one could rewrite the nonfinite phrase with a finite clause with if, such as if it were not for good magazines... but the rewritten if- condition sounds more redundant and less direct. Moreover, the corresponding if-conditions would not have as strong impact as the author's repetitive use of without. The adverbial renders the expression more compact but still functions as a subordinate structure, like an if- condition.

\subsection{Anaphora- would.}

Sometimes, the hypothetical condition is implicit in a pronoun (it, that). These anaphora- would co-texts are often used to evaluate or assess the hypothetical suggestions, as seen in the example below.

(4) Marilyn: well we could make.

Pete: I mean, that doesn't matter, I suppose [it just]

$$
\text { Marilyn: [oh], you know what, }
$$

We have this neat [island] man [go sauce].

Roy: [fields] 
Pete: $\quad[\mathrm{Mm}]$.

Roy: $\quad[($ sneeze $)]$

Marilyn: Chutney [sauce].

Roy: [Chut]ney

Marilyn: That would be good (Frazier, 2003, p. 458, SBC)

In this example, the pronoun that in the last line refers to the suggestion of using chutney sauce and the ensuing would phrase is used to assess that hypothetical suggestion.

\subsection{Generic noun phrases (indefinite article + noun)- would.}

The conditionals are also marked by indefinite references, also sometimes known as generic noun phrases. In the examples below, the noun phrases used as alternative conditions are subject-positioned in would-clauses which indicates the consequences of the conditions.

(5) A man of sense would not do such a thing. (Quirk et al, 1985, p.1091)

(6) Any person who behaved like that would have been dismissed.

Here, because the nouns with indefinite articles ( $a$ or $a n y)$ do not specify actual people, they instead have a hypothetical sense. The possible full conditionals may be If he were a man of sense, he would not do such a thing, and If a man had behaved like that, he would have been dismissed. Compared to clauses with if, these alternative expressions are shorter and more condensed by nominalization. Their shorter length seems to give them a more stingy tone than the longer rewritten if-condition clauses. The above examples (5 and 6) are decontextualized sentences with very conventional meaning, which may not occur in real contexts. Thus, consider now a text with a surrounding context that provides concrete references for elements in the following hypothetical would-clause. 
(7) Richard's view of the aesthetic experience might constitute a sixth variety: for him it constitutes, in part, the "organization of impulses." A sketch of the emotional value of the study of literature would have to take account of all of these (Frazier, 2003, p. 456).

In this example, the indefinite reference to a sketch refers to a figurative one. Unlike the examples above, if the reference to these (i.e., impulses) were not provided, the meaning of the would-clause would be uncertain. Frazier says that such impulses serve as the necessary contextual clue for juxtaposing the real element (emotional value) in the sentence with the hypothetical a sketch. This shows the way language takes advantage of contexts to make individual particular grammatical forms interpretable.

\subsection{Gerund-would.}

Frazier makes note of how alternative conditions marked by gerund structures carry tones that are different from their corresponding if-conditions.

(8) How well do faculty members govern themselves? There is little evidence that they are given any systematic thought to a general theory of the optimum scope and nature of their part in government. They sometimes pay more attention to their rights than to their own internal problems of government. They, too, need to learn to delegate. Letting the administration take details off their hands would give them more time to inform themselves about the education as a whole, an area that would be benefit by more faculty attention (Frazier, 2003, p. 457). 
One could rewrite the underlined sentence to if they let the administration take details off their hands, they would have more time to inform themselves... However, converting the gerund into the possible corresponding if-condition creates a different pragmatic tone. While the if-construction implies a relatively low level of confidence toward the realization of the condition, nominalization carried by -ing suggests more certainty of the writer regarding the possibility of the condition. Frazier indicates that a gerund construction does not affect the hypothetical meaning of the conditional by stating that the "only hypothetical marker is the would construction itself" (p. 457) in the above example. Along with the aforementioned syntactic structures (nominalization), "reified" (Bolinger, 1968, p. 124) meaning inherent in gerund construction seems to contribute to its low level of hypotheticality. Different semantic attributes between gerund and infinitive constructions may explain the reason infinitive constructions have a distinct implication in terms of hypotheticality even though it is in a nominalized form like gerund constructions.

\subsection{Infinitive- would.}

Bolinger (1968) suggests a semantic contrast between the nominalizations carried by -ing and those carried by the infinitive. Specifically, gerunds denote reification at the subject position whereas to- infinitive represents hypothesis and potentiality. Even earlier, Jespersen states that "the infinitive seems more appropriate than the gerund to denote the imaginative" (1940, p. 166, cited from Bolinger). Quirk et al (1985, p. 1191) also associate the infinitive with the expression of hypothesis. To illustrate, consider the following example: 
(9) If there is nothing evil in these things, if they get their moral complexion only from our feeling about them, why shouldn't they be greeted with a cheer? $\underline{\text { To }}$ greet them with repulsion would turn what before was neutral into something bad; it would needlessly bring badness into the world; and even on subjectivist assumptions that does not seem very bright. On the other hand, to greet them with delight would convert what before was neutral into something good; it would bring goodness into the world (Frazier, 2003, p. 456-457).

Here, the discourse started in real conditions is followed by possible consequences evoked by the condition. As the writer supposes two conflicting and unresolved possibilities, he discusses them in unreal conditions. He then uses the infinitive phrases (to greet) to trigger the transfer from the real condition to the unreal and imaginative condition. According to Frazier, the infinitive structure implies "the direct hypothetical conditions leading to the would-clauses" due to the sense of hypotheticality underlying the structure. His remark about infinitive structures contrasts sharply with a previous assumption that a gerund structure is not a factor in determining the hypothetical meaning of the consequent would clauses. In other words, though both infinitive and gerund structures serve as a condition of the consequential would clauses in nominalization, their degree of hypotheticality is not equivalent because of their different semantic properties.

Frazier's claim that infinitive structures (and if-clauses) are more hypothetical and more concessive than gerund structures (p. 457) is supported by Duffley's study of the ing and to-infinitive in the function of subject, based on Brown (AE) and LancasterOslo/Bergen (BE) corpora (2006). Duffley provides empirical evidence regarding the distinction between to infinitives (hypothesis) and gerunds (reification), such as the 
finding that context evoking non-realized events are much more associated with toinfinitive than with gerund construction. There are also many more conditional contexts (27 vs. 8) with to-infinitive than with -ing. Duffley's corpus study is worth noticing because it shows the real comparative uses of two structures with similar functions, which had been studied only theoretically in traditional linguistics.

The survey of each alternative conditional shows that even though alternative conditions can be converted into if-conditions while retaining their propositional meaning, their structural differences create different pragmatic tones and degrees of hypotheticality. That alternative conditionals convey certain pragmatic functions probably accounts for the frequent occurrence of these features in written registers. In written genres, writers strive for variety along with coherence. They choose alternative forms over if-conditions to diversify their style of writing while pursuing more compact expressions as in example 9, which illustrated how if-conditionals are followed by infinitive constructions which have almost the same effect as if-conditions. On the other hand, as noted, gerund structures have a tone that is quite different from that of their corresponding if-conditions. Thus, the common occurrence of alternative types in written English may be explained in terms of strategic choices associated with each type of alternative forms.

\subsubsection{No-overt conditionals ${ }^{5}$ (lexico-grammar).}

Along with the alternative structures for if-conditions, Frazier's corpus study also provides co-occurring patterns of no-overt conditionals. Because Frazier excluded tokens

\footnotetext{
${ }^{5}$ This term is given by Frazier (2003). In his study, no-overt conditionals refer to wouldclauses with epistemic meaning. The term, epistemic, is "concerned with matters of knowledge or belief" (Lyon, 1977, p.793) and more specifically used for referring to the speaker's opinion or attitude towards the verity of the proposition.
} 
that carry polite volitional meaning, his study only treated no-overt conditionals that carry epistemic meaning of would. In no-overt conditionals, certain lexical items tend to occur with particular grammatical features. ${ }^{6}$ Stative verbs such as seem and suppose, often occur with an epistemic would. As seen in the examples, It would seem there has been a mistake; one would suppose the danger is over, one can use these sentences with the hypothetical would. The function of the hypothetical form (would) here is "to distance the speaker's claim even further from reality" (Leech, 2004, p. 132).

Frazier especially noted a co-occurring pattern of a hypothetical modal verb would and copula seem.

(10) It would seem that much of the furor over drug costs has been misplaced (Leech, 2004, p. 131)

The underlined verb phrase can be replaced by the indicative form of the verb, seem. The verb seem already has a hedge function, but the combination (hypothetical would + tentative copula, seem) doubles the tentativeness. That is, it seems already shows a lack of confidence, and the compound hedge, it would seem, takes an additional step in the same direction. Frazier goes even further and suggests a triple hypotheticality including the use of would, the tentative copula seem, and the use of to-infinitive:

(11) First of all there is ample area in East Greenwich already zoned in the classification similar to that which petitioner requested. This land is in various stages of development in several locations throughout the town. The demand for these lots can be met for some times to come. This would seem to indicate

\footnotetext{
${ }^{6}$ The lexical items (seem, never) presented here are not only used with would but also with other secondary modal verbs (e.g. He might seem angry, but that's not true at all.)
} 
that we are trying neither "to halt an influx of migrants" nor are we "setting up such standards for development that only the well-to-do could afford to buy land and build in the new sites. (Frazier, p.454)

The triple hypotheticality is created by the last element, to infinitive, which, as discussed earlier, often carries a feature of hypothesis or potentiality. However, the collocation of would and seem does not always refer to a degree of uncertainty or lack of confidence. Moreover, this expression is sometimes associated with interpersonal strategic functions in speaking/writing circumstances. By using would as a hedge word, speakers/writers try to reduce the risk of creating opposition toward their claims to make known that their claims are not conclusive (leaving room for negotiating the right representation of the state of knowledge discussed) or to imply politeness as to look humble rather than allknowing (Vazquez and Giner, 2008).

Additionally, Frazier points out that some adverbials that express probability (e.g. maybe, probably) can enhance the tentative stance of the speakers/writers. For example, a TA here says that “... there are different, factors and different choices, that um, you know an advantage maybe there wouldn't be quite as many, um, but there're different, influences, that can, come in" (Frazier, p. 454). As the TA is not a professor, he perhaps does not have the authority to make a definitive comment and thereby weakens his commitment toward the integrity of his statement by adding a tentative tone. Frazier asserts that the adverbial maybe, along with the would structure, is key in the enhancement of TA's tentative stance. 
Another interesting finding regarding lexico-grammatical features is that adverbial negator never is often used with would when speakers/writers show their denial of or disbelief toward a hypothetical or counterfactual possibility. Frazier writes that in his corpus data, all the would structures in these situations were collocated with never. In a conversation about a jury panel, Rebecca tells Rickie that male jury members would not be able to understand women's feelings in a given situation.

(12) Rebecca: Because their [men's] experience would be totally different if a man exposes [himself]

Rickie: [SNIFF]

Rebecca: which, a man would never do that. (Frazier, p.455)

In this example, Rebecca uses never to deny a hypothetical possibility of "a man exposing himself to another man," emphasizing the negativity of the possibility.।

In no-overt conditionals, co-occurrences of hypothetical modal verb would and copula seem carry an intensified tentativeness, which indicates "the speaker's reluctance to commit himself on matters of personal feeling or judgment” (Leech, 1987, p. 120). Also, negativity in these hypothetical contexts is emphasized by a co-occurrence of the hypothetical modal verb would and adverbial negator never. These two patterns shown in no-overt conditionals are used to either amplify or deny the uncertainty.

To summarize section 2.2, I looked at Frazier's corpus findings on hypothetical would-clauses in naturally occurring language, paying attention to two types of wouldclauses: alternative conditionals and no-overt conditionals. The information from the findings showed the frequencies of these would-clause types in real language and the implications of their usage within particular associations. Such empirical evidence could 
contribute to narrowing the gap between real language use and textbook descriptions, by suggesting which grammatical features are to be supplemented during the textbook writing process. In the following section, I review Focus on Form as an approach for teaching the target grammatical features.

\subsection{Focus on Form}

While the corpus study attempts to describe real grammar features of hypothetical would-clauses, Focus on Form is an instructional approach that aims to facilitate the learning of such features. The present study's attention to this approach stemmed from the Korean government's official suggestion that this method be applied to the current curriculum. In addition, as mentioned, the complexity that arises from the form/meaning variety may cause difficulties in learning the features and require learner attention to both form and meaning. Norris (2003) points out that the verb forms in conditional sentences undergo back-shifting and do not retain their normal references to time (e.g. a past verb form in conditional clauses indicates a present situation and denotes hypotheticality or counterfactuality), which can cause ESL/EFL learners some confusion. Then, how can one facilitate the learning of form and meaning of the target language features? In the past, language teaching focused on either form $S$ or meaning/communicative function. A traditional form-centered approach (focus on forms) mainly pursues instruction of discrete language items isolated from communicative contexts. Another prevalent method is a meaning-centered approach (focus on meaning), which aimed to provide learners with plenty of exposure to comprehensible language input and meaningful interactions as that was theorized to be sufficient for language acquisition. Both approaches are flawed in that they put emphasis on only a single area of competence (accuracy or fluency). 
Focus on Form was introduced to compensate for the shortcoming of these two approaches, by focusing learners' attention on forms while making them realize the meaning in the context of communicative activities. The tasks and techniques of this approach enable learners to notice the form-function-meaning relationships by addressing some aspect of language within a meaningful context (Doughty and Williams, 1998). For further understanding of this approach, I reviewed its definition and applications for language teaching, as shown below.

\subsubsection{The history of Focus on Form.}

As mentioned, two types of approach were completely dominant in English language instruction for much of the $20^{\text {th }}$ century. One is a traditional discrete grammatical teaching that had dominance until the 1970s. In this approach, the instructional focus is on drills of discrete language features, which entails isolation or extraction of linguistic features from the context or from communicative activities (Doughty and Williams, 1998). During the 1970s, with doubts about the effectiveness of the form-oriented approach (Widdowson, 1978), language researchers and educators began to look at communicative competence and a meaning-based approach for developing communicative ability in students. The basic premise of a communicative approach is that exposing language learners to as much natural language input as in first language acquisition will allow learners to acquire grammar rules from the comprehensible input (Krashen, 1982). Language teaching with a communicative syllabus is still favored in many language classrooms; however, there have been many counter-arguments to an entirely meaning-focused approach. 
Many SLA studies show that English learners studying under curricula only

focused on meaning and communication are unlikely to attain native-like written and oral proficiency. Studies of French immersion classes from the 1980s and 1990s in Canada (e.g. Harley and Swain, 1984; Swain, 1985; Swain and Lapkin 1995, etc.) indicate that even though many students achieved native-like comprehension skills, their written and oral production skills remained far behind native-norms (Millard, 2000). Millard, using Spada and Lightbown's studies as examples, asserts that students in CLT-based intensive ESL programs failed to acquire grammatical accuracy while their fluency was significantly superior to that of their counterparts in more traditional programs. These findings led SLA educators and researchers to pay more attention to language forms that previously were overlooked in CLT.

Accordingly, Focus on Form, first proposed by Long (1991), was regarded as an alternative to a meaning-centered approach. Focus on Form does not necessarily mean a regression to isolated grammar teaching. Rather, it aims to "draw learner attention to form but is not isolated from communication" (Doughty and Williams, 1998, p. 197).

\subsubsection{Application of Focus on Form: From implicit learning to explicit instruction.}

While Focus on Form pursues the middle ground between form-centered instruction and meaning-oriented approach (Gascoigne, 2001), it was first proposed as a reaction to CLT from the idea that increasing learners' attention to language form is critical for the learning to take place. In this regard, 'attention to form' may be key in conceptualizing Focus on Form in terms of how it is applied to language pedagogy. Doughty and Williams (1998) categorized implicit and explicit learning based on whether 
the attention of the learners are "attracted" or "directed" to language features; the aim of implicit Focus on Form is to attract learner attention and avoid metalinguistic discussion so that any interruption to the communication is minimized. In contrast, explicit teaching aims to direct learner attention and to make use of pedagogical grammar. Accordingly, they arrange Focus on Form tasks and techniques on various locations throughout the implicit-explicit continuum. Figure 1 was modified from Doughty and Williams' taxonomy (1998) and Doughty's continuum (1991), which ranges from the most implicit input flood to the most explicit metalinguistic explanation.

\section{Figure 1.}

\section{Implicit-explicit Continuum of Focus on Form Techniques (based on Doughty and}

Williams's Focus on Form taxonomy, 1998)

\begin{tabular}{|c|c|c|c|}
\hline Implicit learning (attracted) & & Explicit learn & $\operatorname{g}$ (directed) \\
\hline $\begin{array}{l}\text { Input Input Recast Output } \\
\text { flood enhancement } \quad \text { enhancement }\end{array}$ & Dictogloss & $\begin{array}{l}\text { Consciousness } \\
\text { raising }\end{array}$ & $\begin{array}{l}\text { Explicit } \\
\text { explanation }\end{array}$ \\
\hline
\end{tabular}

In implicit learning, learners are expected to induce rules from the given examples so noticing forms in the input would be a prerequisite for learning. Input flood is located at the implicit extreme end of the Focus on Form technique, in which learners are presented with a "flood" of the target language input as to increase the possibility of learners taking notice of the features. Another way to enhance noticing forms in the input is the use of input enhancement. This technique, which makes forms perceptually salient through methods such as color-coding, bold, italic, and font manipulation, is still at the implicit end of the continuum. 
Recast and output enhancement more directly draw learners' attention to form, which is often achieved by teacher's intervention (e.g. teacher's reformulation or clarification request on the students' utterance including deviant forms). Thus, these types of tasks incidentally draw learner attention to language form and prioritize meaning-making over correct output of the target form.

The degree of explicitness of attention to form is further increased in dictogloss and consciousness-raising (CR) tasks with the inclusion of metalinguistic aspects. Dictogloss and certain CR tasks direct learner attention to target language forms by engaging them in talking about the linguistic features. The process of solving syntactic problems through communicative interaction may help learners fully attend to target language form as well as attain communicative benefits. As for CR tasks, Ellis (1994, 2002) distinguishes them from traditional grammar practice by arguing that CR tasks aim to help learners to formulate explicit knowledge about language features while practice emphasizes repetitions and correct productions. Both dictogloss and CR tasks belong to the preplanned type of Focus on Form. It has been argued that in terms of actual implementation in language instruction, preplanned or proactive Focus on Form is more feasible and practical than incidental or reactive Focus on Form (Barbieri and Eckhardt, 2007).

Located at the explicit end of Focus on Form, metalinguistic explanations are not included in Doughty and Williams' taxonomy (1998). However, metalinguistic information, as an important determiner for separating explicit Focus on Form from implicit, is included in Spada (1997) and Ellis (2010)'s definition of Focus on Form. For this reason, this feature was added to the modified Focus on Form continuum (Figure 1). 
Many studies have attempted to determine which side of the scale is more effective. While there is still same controversy regarding whether explicit information is necessary for facilitating the acquisition or exposure to high frequency is sufficient, empirical evidence generally supports the positive influences of explicit instruction (Gor and Chernigovskaya, 2005).

\subsubsection{The importance of output Focus on Form.}

The previously shown input flood, input enhancements, and metalinguistic explanation are the prime examples of input-based techniques. A consciousness-raising task also belongs to input-based Focus on Form because it does not intend to make students immediately produce the target features. Input alone, though important, is nevertheless not enough for language acquisition. Language classrooms should not only increase information input, but also make learners efficiently output the language that they have learned. As Swain (1985) emphasized, producing output directs learners from semantic processing toward syntactic processing for accurate production. During the output process, learners may notice the difference between what they want to say and what they cannot say in the target language (Swain, 1998). Noticing the gap may be the first step for learners to produce language features in an accurate way. In addition, learners can use their output to try out new language forms while expecting to get feedback from an external source. Such attempts may allow them to see what works and does not work and to obtain useful information for their inter-language to be modified or reprocessed.

Swain (1998) proposed metatalk, the explanation of language using language, as another function of output. The importance of the proposal is that metatalk is encouraged 
in contexts where learners are engaged in "making meaning", which may help learners become aware of the "forms, rules, and the relationship of the forms and rules to the meaning they are trying to express (Swain, 1998, p.)”. Thus, producing language in meaningful contexts is vital for learners in evolving their inter-language toward targetlike forms along with negotiating meaning.

EFL students have limited opportunities to produce English language output in extracurricular settings. The various output tasks such as dictogloss could provide them with an optimized learning context that links form, meaning, and use, as learners are encouraged to consciously engage in paying attention to forms while making meaning in collaborative works.

\subsubsection{Direct approach: Application of Focus on Form to a range of linguistic levels.}

Doughty and Williams (1998) point out that in most cases, SLA studies have been only applied Focus on Form to IL sound systems, syntax, and morphology, neglecting other levels of linguistic form. However, every hierarchical level of language - from phonology to morposyntax to the lexicon to discourse and pragmatics - is composed of both forms (e.g. phonemes, morphemes, lexical items, cohesive devices, and politeness markers) and rules (e.g. devoicing, allomorphy, agreement, collocation, anaphora, and ingroup vs. out-group relationships) (Doughty and Williams, 1998), so these levels of linguistic form ${ }^{7}$ should be regarded as potential candidates for Focus on Form. They especially note the efficacy of a direct instructional approach (when compared to that of purely meaning-focused instruction) on these levels of linguistic form.

\footnotetext{
${ }^{7}$ Form is used as a comprehensive term including both forms and rules.
} 
One recent study (Nguyen et al, 2012) shows the effectiveness of a direct approach on the development of L2 pragmatic competence. In the experiment, sixty-nine Vietnamese learners of English were divided into three groups; control group, explicit (or 'direct') group (receiving explicit meta-pragmatic explanation and correction of errors in forms and meanings), and implicit group (receiving pragmalinguistic input enhancement and participating recast activities). The results show that both the implicit and explicit treatment groups outperformed the control group and still maintained improvement in the delayed posttest. The most notable finding in this study is that the explicit group performed significantly better than the implicit group by all measures. Thus, while students benefit from both implicit and explicit Focus on Form instruction in terms of pragmatic development, explicit instruction seems to be much more effective. The study suggests that L2 pragmatics is teachable and that explicit instruction is beneficial to L2 pragmatic development.

The present study includes the examination of different communicative functions of would-clauses from pragmatic and strategic standpoints. While learners may be able to notice the pragmatic and strategic functions in the contexts of use, they would also benefit from the direct instructional approach for clearer understanding of the functions associated with the target language forms.

\subsection{The Summary of Literature Review}

After briefly surveying the current Korean English curriculum, the literature review addressed two strands of research relevant for this study: Frazier's corpus-based study of hypothetical would-clauses (2003), which was the academic motivation for this 
study and Focus on Form, an instructional method seen as important by the Korean Ministry of Education.

For the first strand, I started by discussing the concept that corpus studies of grammar can contribute to grammar teaching or textbook writing by providing information about grammar use based on empirical evidence. And then I identified corpus findings of the grammar features targeted in the present study. Frazier's corpus study shows that hypothetical would-clauses often occur without corresponding ifconditions and that the two types of these conditionals (alternative conditionals and noovert conditionals) occupy a significant portion in naturally occurring language. Additionally, the corpus study provides functional information associated with the use of the two aforementioned would constructions. For example, in grammatical co-text patterns of alternative conditionals, each combination of a variety of conditional structures and would-clauses has its own functions and may create different pragmatic values (different degree of hypotheticality). Also, would connected with specific lexical items (seem or never) intensifies or negates the degree of uncertainty. Thus, this part of the literature review was devoted to reviewing the corpus findings of these two types of would-clauses without if in terms of their frequency, grammatical patterns, and register variations. The summarization is shown in Table 2 .

\section{Table 2.}

Summary of Corpus Findings about Two Types of would-Clauses

\begin{tabular}{lll}
\hline & Alternative conditionals & No-overt conditionals \\
\hline Frequency & $59 \%$ & $15 \%$ \\
\hline Grammar pattern & grammatical co-text (grammar- & lexico-grammar (grammar- \\
& grammar) & word) \\
\hline Register & more common in written texts & more common in spoken texts \\
\hline
\end{tabular}


While corpus studies provide textbook writers with empirically validated information about grammar, Focus on Form suggests a teaching method that can more effectively enhance students' ability to understand the grammar. Regarding the target grammatical features provided by the corpus study, Focus on Form would allow students to grasp both form and meaning, which would be especially important because of the inherent complexities of the target features' form and meaning.

I looked at how Focus on Form is applied to instructional techniques/tasks from two viewpoints. Focus on Form techniques and tasks occupy different locations on the implicit-explicit instruction continuum. While there is still controversy over whether an implicit or explicit approach is superior, many studies indicate the effectiveness of explicit instruction. Explicit instruction is directed at ensuring that learners have explicit knowledge about the target structures, which can accelerate the process of noticing the input feature and taking it as implicit knowledge.

Additionally, research shows that output based Focus on Form should be also thoroughly implemented because it can help learners use the language that they have learned with more accuracy. Through the output process, learners can notice the gap between what they want to say and what they are able to say, test new language forms and receive corrective feedback, and develop their interlanguage toward the target-like forms within the context of meaning negotiation.

Figure 2, a modified version of Doughty and Williams (1998)'s taxonomy, shows the implicit-explicit continuum as well as the output mode information. 


\section{Figure 2.}

\section{Focus on Form Techniques/Tasks Based on Explicitness and Output Mode}

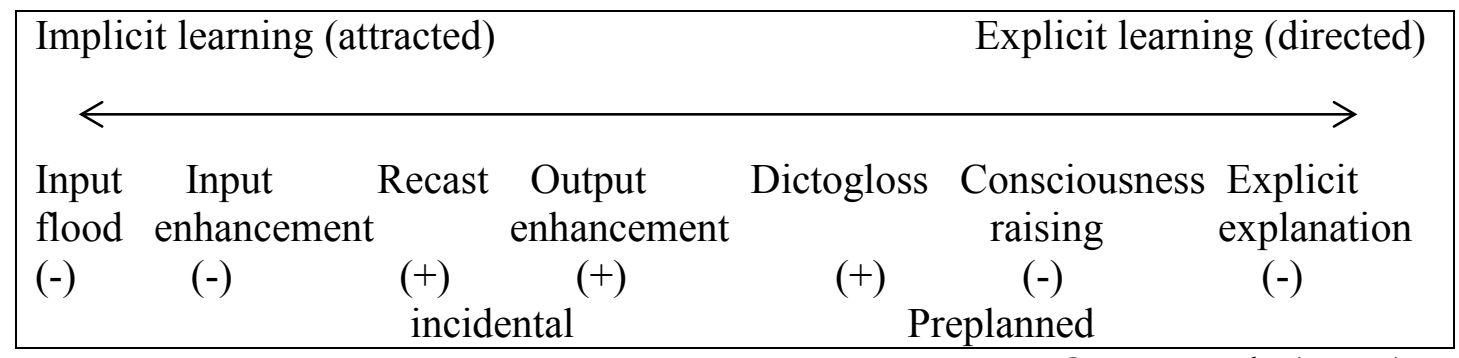

Output mode (+ or -$)$

In the literature review, I have surveyed the use of the target grammatical features in naturally occurring language and a teaching approach that attempts to integrate two traditional teaching methods. These two topics, as the theoretical backgrounds of this study, will be the basis for analyses and discussions of this study.

\subsection{Research Question}

The research for this thesis was inspired by a corpus based study (Frazier, 2003) which argued that hypothetical would-clauses often occur without any corresponding ifconditions. It showed that instead, hypothetical/counterfactual conditions are either implied in the contexts or marked by grammatical structures other than if. The study also indicates that a considerable number of epistemic would-clauses without overt conditionals are used in naturally-occurring language. These findings were novel to me, an English language learner, since I had been taught in EFL classes where would-clauses are usually highlighted either with if-conditions or with polite volitional meaning. The corpus study led me to question whether what is taught in the classroom reflects what is actually used in genuine texts. For this reason, I examined the way current Korean high school English textbooks treat hypothetical would-clauses, further focusing on the two 
types of would-clauses without if-conditions (alternative conditionals and no-overt conditionals) discussed in the corpus study. A comparison of the textbook descriptions with the corpus findings was conducted to determine whether the features in the textbooks are addressed as they are used in naturally-occurring language.

The other issue of this study is related to an English teaching approach adopted by the Korean Ministry of Education to address the limitations of purely meaning-centered language teaching methods that overemphasize fluency over accuracy. The main idea of this approach is to encourage learners to pay attention to certain language forms while keeping them focused on communication. In this regard, another important issue in this study is to see whether the Korean textbooks are optimized for presenting target language features with respect to Focus on Form approach.

As such, corpus linguistics and Focus on Form pedagogy are theoretical and analytical frameworks for this study. Based on these two issues, I investigated Korean EFL textbooks to determine to what extent they provide the target language features consistent with the real language use and whether the features are presented in a way that facilitates learning, with respect to Focus on Form. Thus the research questions are as follows:

1. To what extent do the textbooks reflect the real use of conditionals as described in Frazier's corpus study in terms of

a) frequency of all would-clause conditionals and

b) the grammar patterns of the alternative and no-overt conditionals?

2. Are would-clause conditionals in the Korean textbooks presented in a way that draw learners attention to form as recommended by the Focus on Form approach? 


\section{Chapter 3: Methodology}

This chapter provides the rationale behind the textbook selection as well as the procedure for the analyses of the textbooks for answering the research question. The chapter also provides some reference information about the features that were analyzed.

\subsection{Material}

\subsubsection{English textbook of senior course.}

The material for this study consists of five different Korean high school English textbooks. The Korean high school English curriculum contains three levels of textbook: 'High school English' for tenth grade, 'High school English I' for eleventh grade, and 'High school English II' for twelfth grade. Among these, the 'High school English II' textbooks were selected for analysis because it seems that more advanced classes would cover would-clauses with and without if-conditions. According to the guidelines discussing the goal of the high school English II curriculum, the junior (English I) and senior course (English II) both pursue a development of basic interpersonal communicative skills (BICS) and cognitive academic language proficiency (CALP). This may be due to the fact that many Korean universities have started presenting lectures in English, regardless of major, in the name of globalization. Therefore, English II focuses on the language ability needed for a variety of academic research (humanities, sciences) and cognitive/interpersonal communication abilities used during lecture sessions. In this regard, the study also investigates the level of adequacy in which the textbooks meet the goal of the English II curriculum in terms of the target language features. 


\section{Textbook selection.}

The five textbooks for the high school English II curriculum selected for this study were selected because they are the most commonly used textbooks in Korean high schools. For the sake of convenience, each textbook is represented by the letters: KE1, KE2, KE3, KE4, and KE5. Although the Korean Ministry of Education does not make an official announcement about the market share of each textbook publisher, a financial news article reported that KE1 occupies $44 \%$ of the high school English textbook orders in 2010 (Lee, 2010) and an official from the textbook division of the Ministry of

Education confirmed that the aforementioned five textbooks occupy about $70 \%$ of the total school English textbook market ([Park, H.S], personal communication, [November, 2010]). The five textbooks selected are presented in Table 1 below.

\section{Table 3.}

\section{Textbooks}

\begin{tabular}{lllll}
\hline & Textbook & Publisher & Author & $\begin{array}{l}\text { Occupation (\%) } \\
\text { of market share }\end{array}$ \\
\hline KE1 & $\begin{array}{l}\text { High school } \\
\text { English II }\end{array}$ & $\begin{array}{l}\text { Neungyule } \\
\text { Educations }\end{array}$ & Kim, S. K. et al & 44 \\
\hline KE2 & $\begin{array}{l}\text { High school } \\
\text { English II }\end{array}$ & $\begin{array}{l}\text { Doosan Dong-A } \\
\text { Corporation }\end{array}$ & Kim, D. K., et al 26 (combined) \\
& $\begin{array}{l}\text { High school } \\
\text { English II }\end{array}$ & $\begin{array}{l}\text { Geumsung } \\
\text { Publishing }\end{array}$ & Kyan, O.R., et al \\
\hline KE3 & High school & Jihak Company & Kim, K. G., et al \\
& English II & & \\
\hline KE5 & High school & Cheonjae & Lee, C. S., et al \\
& English II & Educations & \\
\hline
\end{tabular}




\subsubsection{Corpus-based study.}

The corpus findings used for comparison are taken from Frazier (2003). As discussed in section 2.2, this article addresses the forms and functions of hypothetical would-clauses from the analysis of one written corpus (the Brown Corpus) and two spoken corpora (the Santa-Barbara Corpus of spoken America English (SBC) and the Michigan Corpus of Academic Spoken English (MICASE)).

\subsection{Procedures}

\subsubsection{Classification of the three types of would-clause.}

First, I determined limits for my search. The focus of this study is on hypothetical would-clauses that are not past time forms of will. As such, I have searched for every clause containing the term would (including its contracted form'd) and eliminated the tokens used for reasons outside the scope of the study. The excluded tokens:

1. Past time reference of will ${ }^{8}$ (especially in reported speech (or indirect speech) that requires the sequence of tense rule, e.g. I said he would come tomorrow.)

\footnotetext{
${ }^{8}$ It is not easy to make a clear distinction between historical past tense of will and the tentative use of would. Palmer (1990) discussed this problem extensively. See the following example.

I didn't realize that would be your area. It absolutely isn't mine.

By the sequence of tense rules, the underlying direct form could contain either will or would. In other words, what he failed to realize could be either 'that will be your area' or 'that would be your area.' Palmer reached a conclusion that the latter seems to be more appropriate because will may suggest a conclusion rather than more probability. However, the former also may be possible. Since a clear criterion cannot be made for these cases, I decided not to include all fuzzy tokens of indirect speech in this study.
} 
2. Would used for habitual past (mostly in narrative, e.g. Kate's office was all the way on the other side of town, and every evening it would take her over two hours to make her way home.)

3. Polite formulaic expressions, which were excluded by Frazier on the basis of being "near-frozen idiomatic expressions rather than novel syntactic structures" (p. 477) (e.g. Would you move your car?)

After sorting out the excluded tokens, I determined the types of would-clauses I would search for. The classification was based on Frazier's own method (by conditional category). First, would-clauses occurring with if-conditions are classified as 'if conditionals.' Second, would-clauses that occur with grammar structures other than if in the conditional clauses (e.g. anaphora, generic nouns, gerunds, infinitives, adverbials) marking conditions are referred to as 'alternative conditionals.' Alternative conditionals also include would-clauses in which conditional clauses are implied within their respective contexts (marked by Ø). Third, would-clauses that occur without any overt implication of conditional meaning are referred to as 'no-overt conditionals.' Thus, a total of three types were selected for analysis: if conditionals, alternative conditionals, and noovert conditionals.

In terms of form, the last two of the three mentioned cannot always be distinguished based on external form; 'alternative conditionals' with an implied conditions and 'no-overt conditionals' are found to have the same form. Therefore, as shown in table 4, I defined implied conditionals as ones in which conditions can definitely be retrieved from the context and no-overt conditionals as ones in which 
conditions are difficult to identify from the context. In example (14) below, one can suppose a suppressed condition (e.g. if my observations are correct), but the condition is vague and non-overt. When would is used to express tentativeness, it is difficult to overtly identify the conditions from the context, so I classified it as no-overt conditionals.

\section{Table 4.}

\section{Classification of would-Clauses with Same Forms}

\begin{tabular}{|c|c|c|}
\hline $\begin{array}{l}\text { Conditional type }(\varnothing- \\
\text { would) }\end{array}$ & Implied condition $(\varnothing)$ & would-clauses \\
\hline Alternative conditionals & $\begin{array}{l}\text { (13) (if we show crossing } \\
\text { over): retrieved from the } \\
\text { context }\end{array}$ & $\begin{array}{l}\text { Um, alternatively, we could show } \\
\text { crossing over okay? And what } \\
\text { that would look like, is let's say, } \\
\text { you had a, reciprocal exchange } \\
\text { between, the A gene on, } \\
\text { chromatids two and three okay? }\end{array}$ \\
\hline No-overt conditionals & $\begin{array}{l}\text { (14) (If my observation is } \\
\text { correct) }\end{array}$ & $\begin{array}{l}\text { When I returned home last night, } \\
\text { the house was in a mess and the } \\
\text { door was hanging open. Burglars } \\
\text { would have broken into the house. }\end{array}$ \\
\hline
\end{tabular}

\subsection{Method for Research Question 1:}

To what extent do the textbooks reflect the real use of conditionals as described in

Frazier's corpus study in terms of a) frequency of all would-clause conditionals and b)

the grammar patterns of the alternative and no-overt conditionals?

The first research question was to examine the level of consistency of the target language features between the descriptions in the textbooks and the information provided by Frazier's corpus study. The question was based on two specific findings of the corpus study regarding frequency and grammar patterns of would-clauses. 
To answer question a), I classified would-clauses in terms of conditional category and made a table for recording the total number and percentage of each type of wouldclauses. And then I compared the frequency count to the findings of Frazier's corpus study. The results showed the degree to which the proportion of would-clause types found in the textbooks is consistent to Frazier's frequency data.

The next question b) was to investigate to what extent the textbooks cover grammar patterns of alternative and no-overt conditionals as used in naturally-occurring language. For each occurrence of alternative conditionals and no-overt conditionals, I classified it by the type of grammatical co-text and lexico-grammar pattern. It was also classified by the register in which it was used. Tokens found in the listening/speaking/communicative activity section were put into the spoken register, while ones found in the reading/writing/grammar sections were put into the written register. I then counted the number of co-text patterns and lexico-grammar patterns used in each textbook. The information indicated how different types of grammatical co-text of alternative conditionals and lexico-grammatical choices of no-overt conditionals were covered in the textbooks.

\subsection{Method for Research Question 2:}

Are would-clause conditionals in the Korean textbooks presented in a way that draws learners' attention to form as recommended by the Focus on Form approach?

The second research question aimed to see if would-clause conditionals were provided in ways that facilitate the learning of language form as well as meaning. To examine the target language features based on the Focus on Form approach, I created tables with reference to Doughty and Williams (1998)'s taxonomy. To begin, I checked 
which task/techniques regarding the would-clauses are covered in the textbooks. Many of the techniques in the taxonomy were not included in the search. First, tasks such as recast, interaction enhancement, output enhancement, and garden paths were excluded because they require incidental corrective feedback during communicative interactions, which cannot appear in textbooks. Negotiation tasks were also excluded, as they occur during commutative interactions. Other techniques, such as task-essential language (e.g. learners must use target structures to complete the task), input processing (e.g. learners are told what to pay attention for and why they must change their processing), and dictogloss (e.g. learners reconstruct the text that they listen to) were not included in the analysis because they were not found in any of the textbooks.

Accordingly, the techniques from the taxonomy, input flood, input enhancement, and consciousness-raising task were determined to be appropriate for inclusion into the analysis table along with explicit explanation. Explicit explanation was included on the grounds of Spada (1997)'s study, which argues that Focus on Form consists of all activities that are utilized to draw learners' attention to language form, both implicitly and explicitly. Her study asserts that the approach includes "direct teaching of language (e.g., through grammar rules) and/or reactions to learners' errors (e.g., corrective feedback)" (p.73). In addition, Ellis (2010) maintains that explicit focus on form includes overt corrections and metalinguistic explanations. Even though Doughty and Williams do not include metalinguistic explanation in the Focus on Form taxonomy, they consider metalinguistic information a factor for determining the features of Focus on Form (1998, p. 258). They exclude tasks that only present isolated metalinguistic information such as a lengthy grammar lecture. A language textbook is not a task or lecture. It should have a 
reference function providing learners with direct approach about the language features. For more complete understanding of the language form and meaning, metalinguistic information should be implemented in the textbooks. In this regard, I incorporated metalinguistic explanations and rule descriptions of the target features under the category of explicit explanation. However, corrective feedback (e.g. recast) that incidentally occurs during communicative interaction is not available in textbooks, so they are not included in the analysis table.

The four techniques can be placed on a continuum from implicitness to explicitness as shown in Figure 3.

\section{Figure 3.}

The Four Focus on Form Techniques Found in the Textbooks

\begin{tabular}{cc}
\hline Implicit $\longleftarrow$ Explicit \\
\hline Input flood Input enhancement $\quad$ Consciousness-raising task Explicit explanation \\
\hline
\end{tabular}

Input flood, the most unobtrusive way to attracts learner's attention is located at the implicit end on the continuum. Input enhancement is also on the unobtrusive side but may lead to a more pedagogical intervention by making the target forms perceptually salient. Consciousness raising tasks, which belong to the explicit side of the continuum, direct learner attention to form. Explicit explanation is, naturally, located at the explicit end of the continuum. I divided the four techniques into two different categories of implicit and explicit learning. Input flood and input enhancement, which attract learners' attention, are under the implicit learning while consciousness raising task and explicit 
explanation belongs to explicit learning category by directing learners' attention. These techniques are exemplified below.

$\underline{\text { Input flood (IF) }}$

Input flood is a way of exposing students to large quantities of a target feature within a text or activity without explicit instruction. The following presents examples of input flood in the reading section of KE3.

\section{Textbook Sample 1.}

\section{pros}

5 In any case, voters are not required to be fully informed or highly intellectual - such a requirement would be elitist and undemocratic. Eighteen-yearolds are, in most other respects, adult members of society.

\section{cons}

5 Voters have a duty to inform themselves and be competent participants in the process of politics and democracy. Voting should not be made available to all but should be restricted to those who qualify. This would not be an elitist measure but would simply ensure that a bare minimum of competence in understanding political ideas was attained. It is a sentimental

\section{(p. 199 in KE4)}

The example above is about a debate regarding the validity of the current voting age.

These texts expose students to the target features three times, all alternative conditionals:

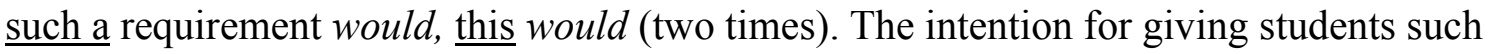
a number of specific feature inputs are to make them implicitly notice the features.

Input enhancement (IE) 
Input enhancement includes the use of typographical enhancements such as putting the target features in bold, italics, underline, or color-coding to increase the perceptual salience of the target features. The following example is excerpted from KE3.

\section{Textbook Sample 2.}

2. Voters are not required to be fully informed or highly intellectual - such a requirement would be elitist and undemocratic.

( $\rightarrow$ If such a requirement were made, it would be elitist and undemocratic.)

A brave soldier would not be frightened by such a threat.

( $\rightarrow$ If a soldier were brave, he would not be frightened by such a threat.)

(p. 203 in KE4)

The bold and underlined elements in the examples above are alternative structures and modal verbs.

\section{$\underline{\text { Consciousness- raising task (CR) }}$}

CR tasks are designed to lead student to notice the target features in the given data, make intellectual efforts to understand the form and meaning of the features, and achieve an explicit understanding of the target features through further data.

\section{Textbook Sample 3.}

1 Look at the pictures and complete the sentences with the phrases below.
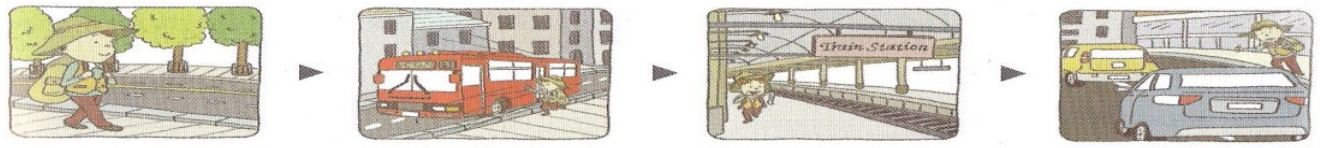

(1) If I had hurried to the bus stop,

(2) If I had caught the bus,

(3) If I had arrived at the station on time,

(4) If I had caught my train,

(a) I wouldn't have missed my train

(b) I would have been in time for the bus

C I would have arrived at the station on time

(c) my journey would have been more comfortable 
The above activity is to an extent similar to traditional grammar exercises (matching test) in that it isolates a specific linguistic feature for focused attention. However, I put it into the CR task category because it has some aspects of a CR task. In order to complete the activity, students need to notice the target form and understand the meanings (negative truth-commitment) associated with the past counterfactual form in the given context (pictures), which makes the activity distinct from traditional grammar exercises that emphasize the repetitions and immediate productions.

\section{Explicit explanation (EE)}

The last technique is explicit explanation, which contains all explicit presentations of language feature information, including metalinguistic explanations and brief rule descriptions.

\section{Textbook Sample 4.}

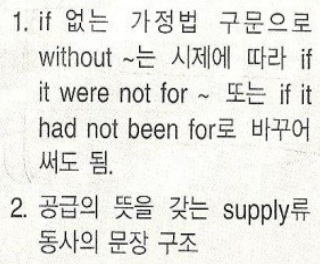

\section{Grammar in Use}

1. Without them, a variety of English could not survive. I would have missed the crucial chance without your help.

(p. 155 in KE2)

Each occurrence of a would-clause was identified and labeled by the aforementioned Focus on Form techniques. I counted the number of the features corresponding to each Focus on Form technique and described how they were presented in the textbooks. This information would show whether the features were given numerous 
enough, presented in a way that draws learners' attention to the form, and provided with explicit explanation. Additionally, I counted the number of exercises to compare them with the number of CR tasks.

The aforementioned tasks or techniques all belong to input-based Focus on Form. Since I could not find any techniques and activities that corresponded to the output-based tasks that appear in Doughty and Williams (1998)'s taxonomy, I looked at the textbook activities concerning the target features and described how the tasks work. After that, I summarized the findings by making comparisons among the input-based techniques on the implicit-explicit continuum and describing the coverage of textbook activities in terms of whether these activities draw attention to form but are not isolated from communication. 


\section{Chapter 4: Results}

This chapter provides the results of the analyses on hypothetical would-clauses used in five Korean high school English textbooks. After reporting the results, I discussed the findings to answer the following research questions: (1) by comparing the textbooks' treatment of would-clauses to those found in naturally occurring language, (2) by examining the ways in which the target features are presented in the textbooks.

\subsection{Research Question 1}

\subsubsection{Real use of conditionals- frequency comparison:}

To what extent do the textbooks reflect the real use of conditionals as described in Frazier's corpus study in terms of frequency of all would-clause conditionals?

For this question, I counted the frequency of would-clauses with if-conditions, would-clauses with alternative conditions (alternative conditionals), and would-clauses without overt conditions (no-overt conditionals) and then compared them with each other. The analysis yielded a total of 253 occurrences of would-clauses (see table 5). Conditionals with if account for $62 \%$ in total, showing the highest frequency of wouldclauses. On the other hand, alternative and no-overt conditionals occupy $30 \%$ and $8 \%$, respectively. 


\section{Table 5.}

Occurrence of the Tokens of would-Clauses in KE Textbooks

\begin{tabular}{|c|c|c|c|c|c|c|c|}
\hline \multicolumn{2}{|c|}{ Conditional category } & KE1 & KE2 & KE3 & KE4 & KE5 & Total $(\%)$ \\
\hline \multicolumn{2}{|c|}{ Conditionals with if } & 18 & 25 & 54 & 36 & 23 & $156(62 \%)$ \\
\hline \multirow[t]{2}{*}{$\begin{array}{l}\text { Conditionals } \\
\text { without if }\end{array}$} & $\begin{array}{l}\text { Alternative } \\
\text { conditionals }\end{array}$ & 10 & 9 & 16 & 25 & 17 & $77(30 \%)$ \\
\hline & $\begin{array}{l}\text { No-overt } \\
\text { conditionals }\end{array}$ & 4 & 4 & 3 & 8 & 1 & $20(8 \%)$ \\
\hline \multicolumn{2}{|l|}{ Total } & 32 & 38 & 73 & 69 & 41 & $253(100 \%)$ \\
\hline
\end{tabular}

(Percentages may not add to $100 \%$ because of rounding)

For comparison with my findings, Frazier's results were organized into the table below. In Frazier's study, if-conditionals account for 25\%, alternative conditionals about $60 \%$, and no-overt conditionals $15 \%$ of the total (including written and spoken corpora).

Table 6.

Would- Clauses by Conditional Category in Frazier's Corpus Study

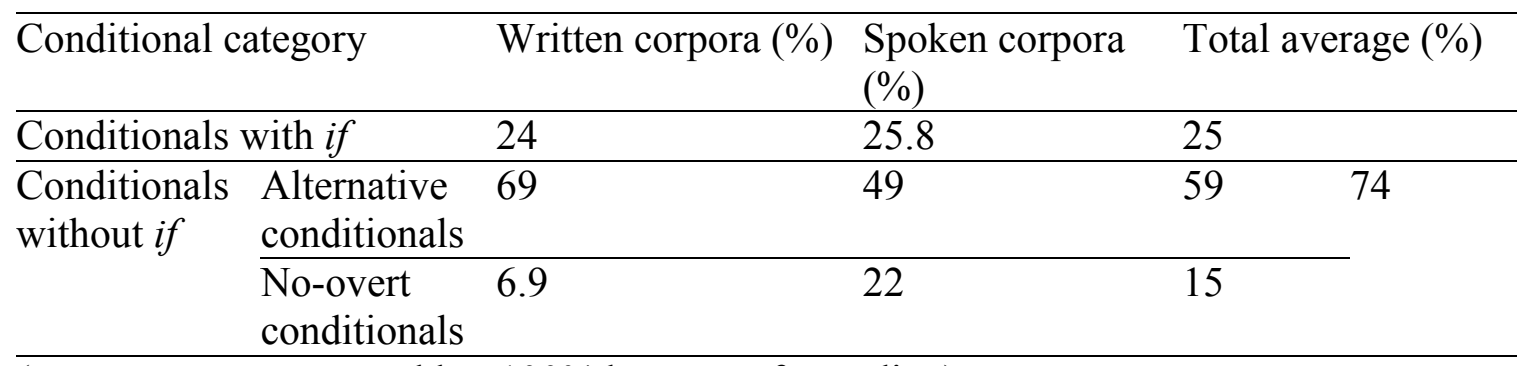

(Percentages may not add to $100 \%$ because of rounding)

Table 5 shows a tendency for every textbook to have a higher frequency of would-clauses with if than without if-conditions. In contrast, in naturally occurring language (table 6), would-clauses without if-conditions occur three times (74\%) as common as would-clauses with if-conditions $(25 \%)$ in both written and spoken corpora. The disparity of percentage between the corpus and EFL textbooks is shown in figure 4. 


\section{Figure 4.}

\section{The Comparison of percentage between Corpus Findings and Korean EFL Textbooks}

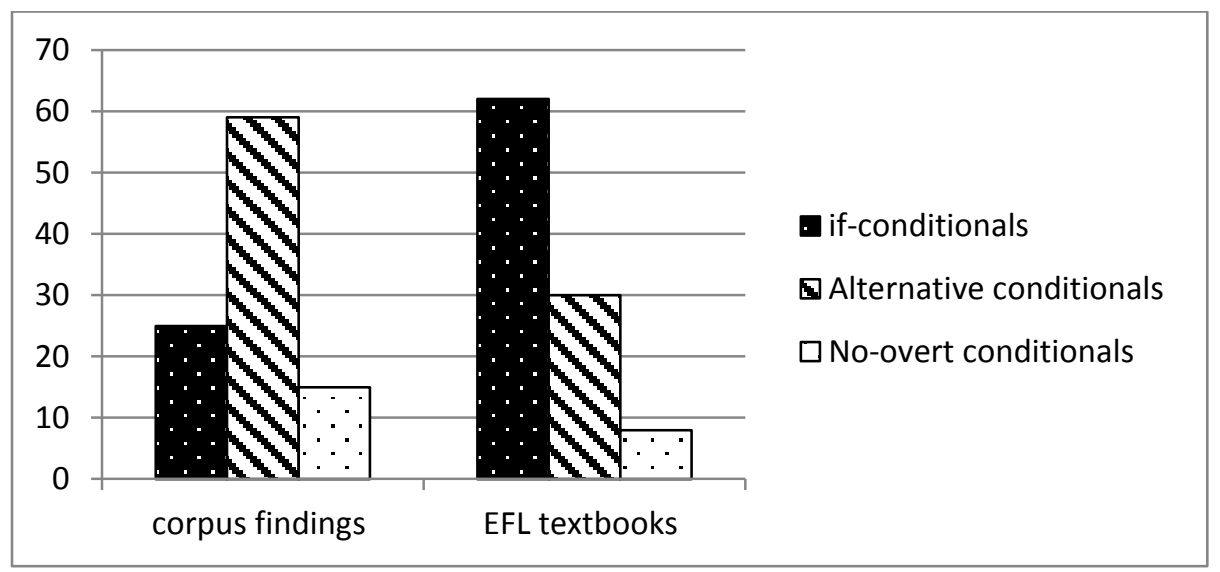

It should be noted that, in Frazier's study, the predominant occurrence of alternative conditionals (about $60 \%$ of the combined average of written and spoken corpora) contributes to the high proportion of would clauses without if-condition. In other words, English language speakers/writers frequently use would-clauses with grammatical structures other than if-conditions. However, the Korean EFL textbooks show a much higher proportion of conditionals with if $(62 \%)$ than alternative conditionals $(30 \%)$, indicating that the EFL textbooks mainly emphasize would-clauses that accompany ifconditions. While alternative conditionals occupy the highest percentage of the entire conditional categories in real language data, the frequency of alternative conditionals in the textbook does not reflect this information. In addition, Frazier's study shows a considerable percentage of no-overt conditionals $(15 \%)$, which is much higher than that found in the textbooks $(8 \%)$. The results suggest that the presentation of would-clauses in the textbooks do not reflect the findings presented in Frazier's study in terms of proportional use. 
The next part of the research question examined the two conditional structures, alternative and no-overt conditionals, in terms of how textbooks cover the grammar patterns of these conditionals.

\subsubsection{Real use of conditionals- grammar patterns:}

To what extent do the textbooks reflect the real use of conditionals as described in Frazier's corpus study in terms of the grammar patterns of the alternative and no-overt conditionals?

For this question, I examined the degree to which textbooks cover the co-text patterns of alternative conditionals and lexico-grammar patterns of no-overt conditionals as seen in corpora.

\subsubsection{Alternative conditionals (grammatical co-text).}

Frazier's corpus findings indicate that people often use would-clauses with grammatical structures other than if-clauses, which means that there are a variety of grammatical co-text patterns. As shown in table 7, each alternative structure carries conditionality but also often creates a different pragmatic value from its if-clause equivalents. It seems that structural substitution (nominalizations) may render these structures more condensed than the corresponding if-clauses. In addition, when conveying conditionality, different grammatical forms of alternative conditions may be associated with varying degrees of hypotheticality (e.g. gerund vs. infinitive). 
Table 7.

Co-text Pattern and Function of Alternative Conditionals (Based on Frazier's Study)

\begin{tabular}{|c|c|c|c|}
\hline $\begin{array}{l}\text { Alternative } \\
\text { structures }\end{array}$ & $\begin{array}{l}\text { Function of alternative } \\
\text { structures }\end{array}$ & Examples & $\begin{array}{l}\text { Common } \\
\text { register }\end{array}$ \\
\hline Anaphora & $\begin{array}{l}\text { Referring to a previous } \\
\text { hypothetical condition }\end{array}$ & That would be good & $\begin{array}{l}\text { Prevalent in } \\
\text { both spoken } \\
\text { and written } \\
\text { data }\end{array}$ \\
\hline \multicolumn{4}{|c|}{$\begin{array}{c}\text { Generic noun Referring to an indefinite } \frac{\mathrm{A} \text { man }}{\text { thing }} \text { of sense would not do such a Common in } \\
\text { hypothetical one }\end{array}$} \\
\hline Infinitive & $\begin{array}{l}\text { Enhancing a sense of } \\
\text { hypotheticality }\end{array}$ & $\begin{array}{l}\text { To greet them with delight would } \\
\text { convert what before was neutral into } \\
\text { something good; it would bring } \\
\text { goodness into the world. }\end{array}$ & \\
\hline Gerund & $\begin{array}{l}\text { Giving a less } \\
\text { hypothetical and more } \\
\text { reified implication to the } \\
\text { sentence }\end{array}$ & $\begin{array}{l}\text { Letting the administration take } \\
\text { details off their hands would give } \\
\text { them more time to inform } \\
\text { themselves about the education as a } \\
\text { whole, an area that would_be benefit } \\
\text { by more faculty attention }\end{array}$ & \\
\hline $\begin{array}{l}\text { Adverbial } \\
\text { (without, } \\
\text { ideally, etc }\end{array}$ & $\begin{array}{l}\text { Hypothesis of non- } \\
\text { existent reality }\end{array}$ & $\begin{array}{l}\text { Without me to supplement your } \\
\text { income, you wouldn't be able to } \\
\text { manage }\end{array}$ & \\
\hline$\varnothing$ & $\begin{array}{l}\text { A condition is implied in } \\
\text { the discourse contexts. }\end{array}$ & $\begin{array}{l}\text { Um, alternatively, we could show } \\
\text { crossing over okay? And what that } \\
\text { would look like, is let's say, you had } \\
\text { a, reciprocal exchange between, the } \\
\text { A gene on, chromatids two and three } \\
\text { okay? }\end{array}$ & $\begin{array}{l}\text { Common in } \\
\text { both spoken } \\
\text { land written } \\
\text { data }\end{array}$ \\
\hline
\end{tabular}

To contrast the findings from Frazier in table 7, table 8 below shows the co-text patterns found in each textbook. I first looked at the level of diversity with which each textbook delivers the pattern. The number in parentheses in each cell indicates the number of sentences with each grammatical co-text pattern. 


\section{Table 8.}

\section{Co-text Patterns Found in Each Textbook}

\begin{tabular}{|c|c|c|c|c|c|c|c|c|}
\hline \multirow[t]{2}{*}{ Co-text } & \multirow[t]{2}{*}{ KE1 } & \multirow[t]{2}{*}{ KE2 } & \multirow[t]{2}{*}{ KE3 } & \multirow[t]{2}{*}{ KE4 } & \multirow[t]{2}{*}{ KE5 } & \multicolumn{2}{|c|}{ Register } & \multirow[t]{2}{*}{ Total } \\
\hline & & & & & & Spoken & Written & \\
\hline Anaphora & $\sqrt{(1)}$ & & $\sqrt{(2)}$ & $\sqrt{(3)}$ & $\sqrt{(3)}$ & 7 & 2 & 9 \\
\hline Generic no & & & & $\sqrt{(14)}$ & $\sqrt{(3)}$ & & 17 & 17 \\
\hline
\end{tabular}

Infinitive

\begin{tabular}{|c|c|c|c|c|c|c|c|c|}
\hline Gerund & & $\sqrt{(1)}$ & $\sqrt{(1)}$ & $\sqrt{(1)}$ & $\sqrt{(3)}$ & & 6 & 6 \\
\hline Adverbial & & $\sqrt{(7)}$ & $\sqrt{(1)}$ & $\sqrt{(5)}$ & $\sqrt{ }(3)$ & 1 & 16 & 16 \\
\hline $\begin{array}{l}\varnothing \text { (implicit } \\
\text { conditionals) }\end{array}$ & $\sqrt{(9)}$ & $\sqrt{(1)}$ & $\sqrt{(12)}$ & $\sqrt{(2)}$ & $\sqrt{(5)}$ & 11 & 17 & 29 \\
\hline Total & 10 & 9 & 16 & 25 & 17 & 19 & 58 & 77 \\
\hline
\end{tabular}

It can be observed from table 8 that there is a huge disparity in variety and frequency of co-text patterns depending on the textbook publisher. KE1 only shows two types of the alternative patterns (anaphora and implicit conditionals). Moreover, as most of the co-text patterns shown in KE1 are implicit conditionals, the textbook shows little diversity of would- clause co-text patterns. The overall frequency of KE2 is lowest among the textbooks and most of the tokens were adverbial- would co-texts. In addition, though KE3 and KE 5 are similar in total frequency, upon a closer inspection, KE5 shows a more balanced distribution, while KE3 almost exclusively presents implicit conditionals. While KE 4 also shows all patterns other than infinitive-would, there is an especially strong concentration of generic- would co-texts. In short, KE1 and KE3, with the exception of 
implicit conditionals, almost never use the patterns identified by Frazier. Additionally, while giving more preferred treatment to certain patterns, KE2 neglects the others.

As pointed out previously, the huge disparity in frequency was also found among different types of co-text patterns. In terms of the global sum of each co-text pattern, the most common pattern, implicit conditionals, occurred 29 times, while the least common, infinitives, did not occur even once. Figure 5 below shows the frequencies of different co-text patterns found in the textbooks.

\section{Figure 5.}

\section{The Varieties of Grammatical Co-text Pattern Found in the Five Textbooks}

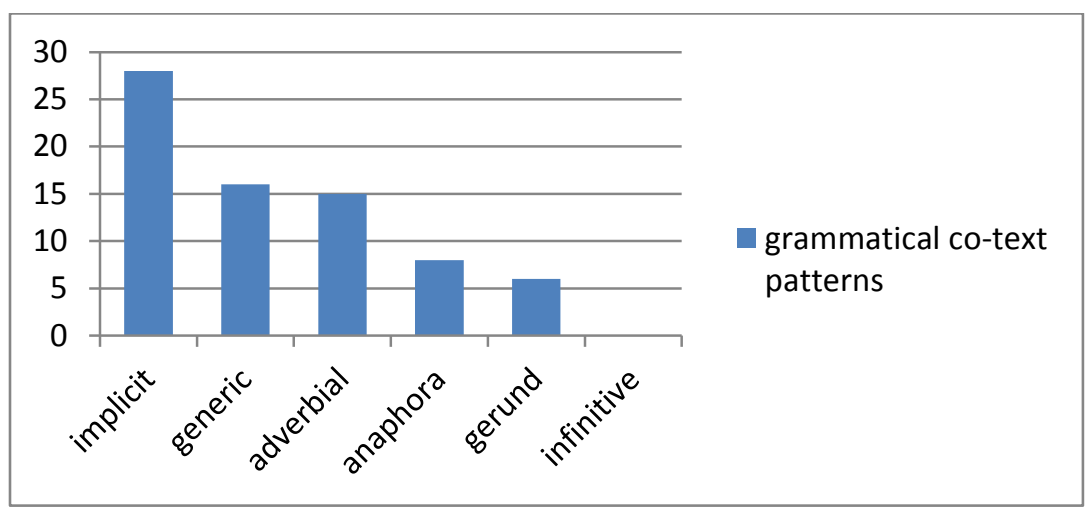

The lack of infinitive constructions in hypothetical contexts is completely inconsistent with the findings of a corpus study (Duffley, 2006), which show that infinitives are fairly common features in hypothetical contexts.

\subsubsection{No-overt conditionals (lexico-grammar).}

Frazier notes certain specific lexical items that often occur with would-clauses when the clauses carry epistemic meaning. The combination of the state verb, seem, and would makes a double hedge, which may be an effective device in lessening the level of certainty and may mitigate the impact of the comments. A similar function is fulfilled by 
certain probabilistic adverbials (maybe, probably). On the other hand, the adverbial

negator never is used when the speaker intends to show his/her denial of or disbelief

toward a hypothetical possibility. The table below presents the form and function of no-

overt conditionals (would-clauses with epistemic meaning) based on Frazier's findings.

\section{Table 9.}

Lexico-grammar Pattern of No-overt Conditionals (Based on Frazier's Study)

\begin{tabular}{|c|c|c|c|}
\hline $\begin{array}{l}\text { Form of } \\
\text { lexico- } \\
\text { grammar }\end{array}$ & $\begin{array}{l}\text { Function of lexico- } \\
\text { grammar }\end{array}$ & Example & $\begin{array}{l}\text { Common } \\
\text { register }\end{array}$ \\
\hline $\begin{array}{l}\text { Would } \mathrm{V}+ \\
\text { probability } \\
\text { adverbials } \\
\text { (e.g. maybe) }\end{array}$ & $\begin{array}{l}\text { Additional marker of } \\
\text { tentativeness besides } \\
\text { would-structures }\end{array}$ & $\begin{array}{l}\text { I mean especially in a, in a really big } \\
\text { society like ours in in a, state society, } \\
\text { um, there are different, factors and } \\
\text { different choices, that um, you know an } \\
\text { advantage maybe there wouldn't be } \\
\text { quite as many, um, but there're different } \\
\text { influences, that can, come in. }\end{array}$ & $\begin{array}{l}\text { More } \\
\text { common in } \\
\text { spoken data }\end{array}$ \\
\hline Would seem & $\begin{array}{l}\text { Amplifies tentative } \\
\text { attitude of the speaker } \\
\text { (double hedge) }\end{array}$ & $\begin{array}{l}\text { It would seem that much of the furor } \\
\text { rover drug costs has been misplaced. }\end{array}$ & $\begin{array}{l}\text { Common in } \\
\text { written data }^{9}\end{array}$ \\
\hline Would neve & $\begin{array}{l}\text { Shows the speaker's } \\
\text { denial or disbelief } \\
\text { toward an } \\
\text { hypothetical } \\
\text { possibility }\end{array}$ & $\begin{array}{l}\text { (assumption based on given information) } \\
\text { A man would never do that. }\end{array}$ & $\begin{array}{l}\text { Common in } \\
\text { both spoken } \\
\text { and written } \\
\text { data }\end{array}$ \\
\hline
\end{tabular}

I found a total of 20 no-overt conditionals across the five textbooks. 15 out of the 20 tokens are used in reading passages, which contrasts with Frazier's corpus findings that no-overt conditionals are common in spoken contexts. In the textbooks, no-overt conditionals occurred the most frequently in KE4 (8 times) and the least in KE5 (1 time),

\footnotetext{
${ }^{9}$ Although Frazier did not categorize would-seem association based on registers, Coates (1983) stated that would seem is often used in written English, so I followed Coates' findings when categorizing this feature.
} 
which both were not very significant for quantitative analysis. Moreover, with respect to lexico-grammar patterns, instances of would and particular word (seem and never) association were very rare. The results of the examination are shown in Table 10.

Table 10.

Lexico-grammar Patterns of No-overt Conditionals Found in Each Textbook

\begin{tabular}{lllllll}
\hline Lexico-grammar & KE1 & KE2 & KE3 & KE4 & KE5 & \multicolumn{2}{l}{ Register } & Total \\
\hline $\begin{array}{l}\text { would + maybe/ } \\
\text { probably }\end{array}$ & $\sqrt{ }(1)$ & & $\sqrt{ }(1)$ & & & 2 \\
\hline would seem & & & & & 2 & 2 \\
\hline would never & $\sqrt{ }(2)$ & & & & 4 & 4 \\
\hline Total & 3 & 1 & & & \\
\hline
\end{tabular}

There were two instances in which would was used with an adverb that expresses probability. Such adverbials (e.g. perhaps and probably) are markers that denote tentative stance in addition to would structures, as seen in the text, where it describes that the strange thing about these impossible questions [to an anthropologist] would probably be [that nobody knows the answers] (p. 87 in KE4). Here, the speaker uses would to develop his opinions cautiously, and adds probably to dilute the level of his conviction to the comments.

The most notable finding of the textbook examination was the total lack of would's appearance with the copula verb seem throughout all textbooks. This association is used not only for indicating lack of confidence on comments but also for expressing humbleness and avoiding strong opposition. Interestingly, despite such wide usages according to Frazier, this double hedge was ignored in all of the textbooks. 
There were just two examples in which the speaker used the association of would and never. In the example of I cannot criticize my parents for hoping that I would never experience poverty (p. 232 in KE1), the adverbial never is used to deny the probability of the hypothetical possibility of experiencing poverty.

The frequency counts of the co-text patterns show that most of the textbooks fail to cover various types of co-text pattern in alternative conditionals. Grammar-word patterns in no-overt conditionals are also almost never presented. The findings indicate that real grammar patterns of alternative and no-overt conditionals were hardly represented in current EFL textbook writing. The next question concerns the presentation method of would-clause conditionals.

\subsection{Research Question 2}

Are would-clause conditionals in the Korean textbooks presented in a way that draws learners' attention to form as recommended by the Focus on Form approach?

For this question, I examined whether the features occurred as frequently as they occur in Frazier's corpus study, are presented in a way that draws learners' attention to the form, and are provided with explicit explanation. In addition, I investigated activities concerning the target features to see if they lead learners to focus on the target form through interacting with other students.

\subsubsection{Focus on Form techniques used for would-clause conditionals.}

\subsubsection{If conditionals.}

As shown in the previous frequency comparison, if conditionals were the most frequent features across all of the textbooks. This shows that the EFL textbooks are generally more concerned with these features than other types of conditionals. The 
complexity of these features arising from their variety of form and meaning requires learners to pay attention to both the language form and meaning. Table 11 shows that both conditional clauses and consequent would-clauses vary in form depending on the temporal and hypothetical meaning. The hypotheticality is realized by adding [+ past] marker to the verbs in bi-clauses. The past perfect form in past counterfactual (17) denotes even further distance from reality as well as indicating past time reference.

\section{Table 11.}

Verb Forms of if Conditionals (Modified from Celce-Murcia and Larsen-Freeman, 1999)

\begin{tabular}{|c|c|}
\hline Meaning & Form \\
\hline $\begin{array}{l}\text { Present (future) } \\
\text { hypothetical }\end{array}$ & $\begin{array}{l}\text { (15) If I had the money, I would buy a house. } \\
\text { [ simple past] }\end{array}$ \\
\hline $\begin{array}{l}\text { Present } \\
\text { counterfactual }\end{array}$ & $\begin{array}{l}\text { (16) If Gandhi were alive, he would be shocked. } \\
\text { [ simple past] } \\
\text { [would }+\mathrm{V}]\end{array}$ \\
\hline Past counterfact & $\begin{array}{l}\text { (17) If you had mowed my lawn, I would have paid you } \$ 5 \text {. } \\
\text { [past perfect] } \\
\text { [would }+ \text { have }+\mathrm{V}+\text {-en }]\end{array}$ \\
\hline
\end{tabular}

Then, do the textbooks present the features in a way that facilitates the noticing of the form along with its associated meaning and use? For this, as mentioned, I examined the way the target features are presented in the textbooks in terms of how they direct learner's attention. The number in each cell in table 12 indicates the number of token (if conditionals) that corresponds to each type of technique. IF shows the number of token inputs, IE shows the number of typographically manipulated tokens, CR shows the number of tokens used for consciousness-raising-tasks, and EE shows the number of explicit explanation (metalinguistic information) relating to the tokens. 


\section{Table 12.}

\section{Focus on Form Techniques Found in if Conditionals}

\begin{tabular}{llllll}
\hline Textbook & IF & IE & CR & EE & Total \\
\hline KE1 & 18 & & & & 18 \\
\hline KE2 & 23 & 2 & & & 25 \\
\hline KE3 & 47 & 7 & 1 & 1 & 56 \\
\hline KE4 & 33 & 3 & & & 36 \\
\hline KE5 & 20 & 3 & & & 23 \\
\hline Total & 136 & 15 & 1 & 1 & 153 \\
\hline
\end{tabular}

IF: input flood, IE: input enhancement, CR: consciousness-raising, EE: explicit explanation.

In this examination, 136 examples of input flood, 15 examples of input enhancement, one examples of CR task, and one example of explicit explanation were found. The figure below shows the frequency of if conditionals found in Korean EFL textbooks organized according to their corresponding Focus on Form techniques.

\section{Figure 6.}

\section{The Frequency of if Conditionals Categorized by Focus on Form Techniques}

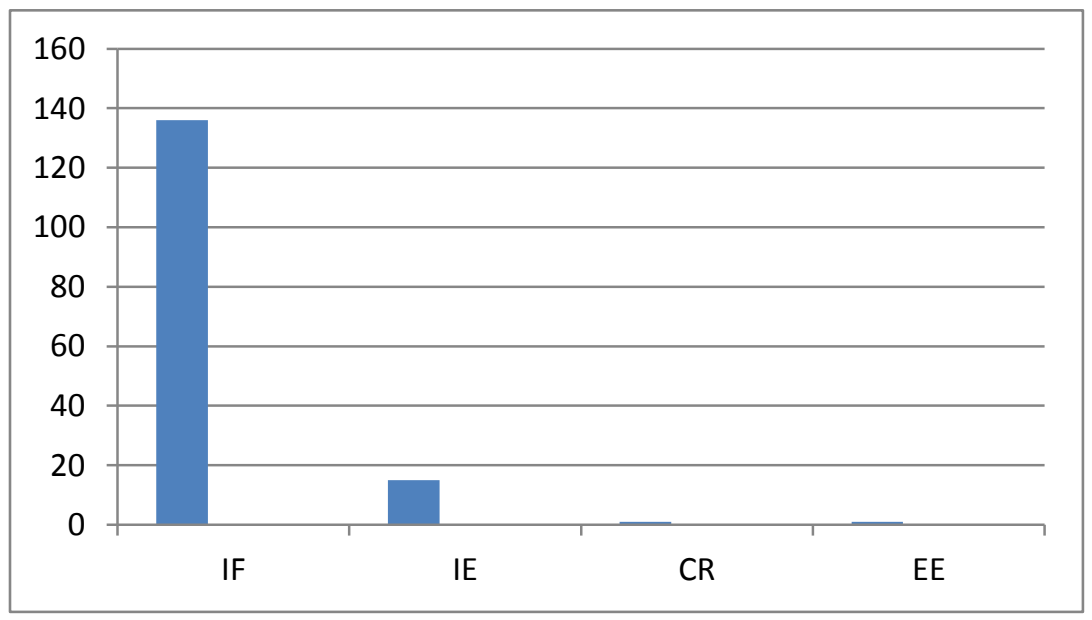


a) Input flood

As figure 6 shows, input flood was the most frequent among Focus on Form techniques. Moreover, input flood of if-conditionals was of greatest frequency among the different conditional types. These findings indicate that if-conditionals are more emphasized than any other types in terms of implicit methods such as input flood. With respect to conditional form, while present hypothetical/counterfactual conditionals takes up about $95 \%$ of the total, tokens of past counterfactual only occupy less than $5 \%$.

b) Input enhancement

With the exception of KE1, all textbooks contained textually enhanced tokens, which mostly consisted of present hypothetical forms. For example, KE5 presents present hypothetical form under the subsection of "Grammar points in use" as follows:

If water were leaking from a faulty tap, it would be repaired immediately. (p. 127 in KE5) The verb forms in both if-condition and would-clause are emboldened to get learner attention, but there is no description about form or meaning. Students are expected to understand the conditional structure by noticing the textual enhanced forms.

c) CR task

CR tasks appear once in KE3. This task attempts to make students to notice the target language form and its associated meaning (e.g. past perfect tense forms imply negative meaning on the past events). 


\section{Textbook Sample 5.}

1 Look at the pictures and complete the sentences with the phrases below.

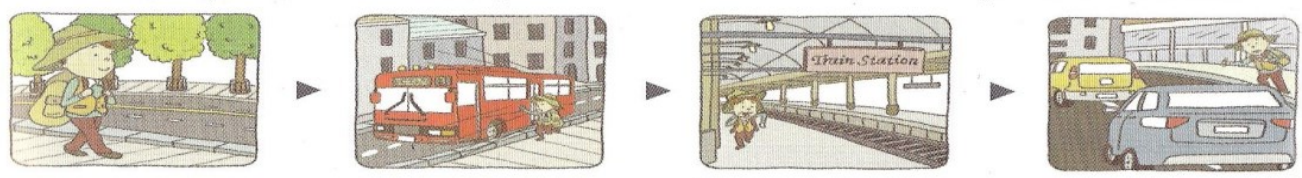

(1) If I had hurried to the bus stop,

(2) If I had caught the bus,

(3) If I had arrived at the station on time,

(4) If I had caught my train,

I wouldn't have missed my train

(b) I would have been in time for the bus

() I would have arrived at the station on time

c) my journey would have been more comfortable

(p. 165 in KE3)

In this task, students are not expected to make immediate accurate production. They are instead expected to attend to the form and meaning to complete the task.

d) Explicit explanation

Explicit explanation about form and meaning appears only briefly in KE3. While KE3 spends two chapters teaching present hypothetical and past counterfactual forms of if conditionals, it does not provide any overt description of form and meaning despite their level of complexity. In the grammar point section of the chapters, the target forms are stressed in bold with references in Korean, which are translated as "subjunctive past" and “subjunctive past perfect," respectively.

\section{Textbook Sample 6.}

(가정법 과거) If I could offer you only one tip for the future, sunscreen would be it.

(가정법 과거 완료) If they had been important to me, I would have remembered them. 
Even though these terms are conventionally used to indicate present hypothetical and past counterfactual, they are too oversimplified and vague for learners to use the conditional forms and understand the temporal/hypothetical meaning.

\subsubsection{Alternative conditionals.}

In alternative conditionals, conditionals are realized by a variety of structures and would-clauses vary in form depending on the time reference and unreal meaning. In these conditionals, while would phrases seem to determine unreal meaning as well as temporal meaning, each alternative structure may also carry a certain degree of hypotheticality. Adverbial phrases in (19) implies an assumption contrary to what is described (i.e. I (will) supplement your income, so you are able to manage). On the other hand, the gerund structure in (18) shows a strong position of the speaker concerning the realization of the hypothetical event. Thus the grammatical forms that need attention for learners are conditional phrases as well as would-clauses.

\section{Table 13.}

\section{Phrase and Verb Forms of Alternative Conditionals}

\begin{tabular}{|c|c|}
\hline Meaning & Form \\
\hline $\begin{array}{l}\text { Present (future) } \\
\text { hypothetical }\end{array}$ & $\begin{array}{l}\text { (18) Getting your book published } \frac{\text { would entail finding an agent. }}{[\text { would }+\mathrm{V}]} \\
\text { [Gerund phrase] }\end{array}$ \\
\hline \multirow[t]{2}{*}{$\begin{array}{l}\text { Present } \\
\text { counterfactual }\end{array}$} & $\begin{array}{l}\text { (19) Without me to supplement your income, you wouldn't be able } \\
\text { to manage. } \\
\text { [adverbial phrase] } \quad[\text { would }+\mathrm{V}]\end{array}$ \\
\hline & $\begin{array}{l}\text { (=if you didn't have me to supplement your income, you } \\
\text { wouldn't... ) }\end{array}$ \\
\hline Past counterfactual & $\begin{array}{l}\text { (20) I replied at once. } \\
\text { To hesitate would have meant suspicion, and he had a tinge of that } \\
\text { [infinitive phrase] [would }+ \text { have }+\mathrm{V}+-e n] \\
\text { already. } \\
\text { (=If I had hesitated, it would have caused suspicion) }\end{array}$ \\
\hline
\end{tabular}


Table 14 shows alternative conditionals found in each textbook categorized into four types of Focus on Form. While input flood has the highest frequency, input enhancement and explicit explanation show very low frequency. Moreover, consciousraising tasks do not appear at all.

Table 14.

Focus on Form Techniques Found in Alternative Conditionals

\begin{tabular}{llllll}
\hline Textbook & IF & IE & CR & EE & Total \\
\hline KE1 & 10 & & & & 10 \\
\hline KE2 & 7 & 2 & & 1 & 10 \\
\hline KE3 & 16 & & & & 16 \\
\hline KE4 & 24 & 3 & & & 26 \\
\hline KE5 & 17 & & & 1 & 79 \\
\hline Total & 74 & 5 & 0 & \\
\hline
\end{tabular}

Additionally, figure 6 shows the frequencies of co-text patterns that were categorized by focus on form.

\section{Figure 7.}

The Frequency of the Co-text Patterns Categorized by the Focus on Form Technique

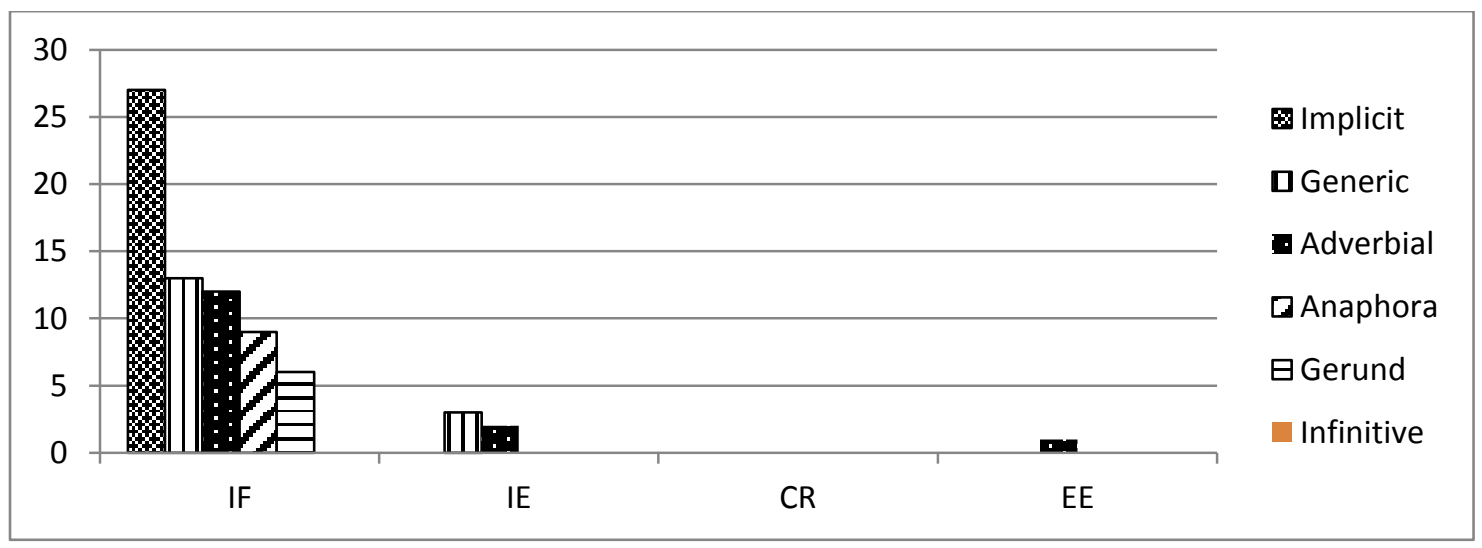


a) Input Flood

As shown in figure 6, three out of six types appear exclusively in input forms. Even though the textbooks provide some texts that include anaphora and gerund-would constructions, the amount of input may be unlikely to have meaningful impact in leading students to notice the form and function of these co-text constructions. Most of the examples occur in present hypothetical situation and only three tokens are found in past counterfactual environments.

b) Input enhancement

Among the five textbooks, only two used the textual enhancement technique (e.g. generic- would and adverbial would co-texts). For example, KE 4's 'Structures in use' section shows examples of conversion from generic-noun phrase to if construction where the target structures were emboldened and underlined to get students' attention, as shown below.

\section{Textbook Sample 7.}

A brave soldier would not be frightened by such a threat.

( $\rightarrow$ If a soldier were brave, he would not be frightened by such a threat)

$$
\text { (p. } 203 \text { in KE4) }
$$

From the example, students are expected to implicitly understand the relationship between the generic-noun alternative conditional and the if-conditional. However, without accompanying overt explanations, this technique may not greatly help students in applying the rules to other analogous structures.

c) Explicit explanation 
Only one textbook (KE2) provided an explicit explanation, which was of how adverbialwould constructions can be converted to if-conditionals:

\section{Textbook Sample 8.}

I would have missed the crucial chance without your help.

Information provided in Korean: if 가 없는 가정법 구문으로 without 는 시제에

따라 if it were not for 또는 if it had not been for 로 바꾸어 써도 됨, which can be translated into "this sentence is a subjunctive mood without if in which without can be changed to if it were not for or if it had not been for, depending on the time reference."

(p. 155 in KE2)

In alternative conditionals, the form of would phrases is often the key informant of the temporal and hypothetical/counterfactual meaning of the conditionals. The above example, as it has the perfect infinitive form, implies the negative truth-commitment toward the past event, but the textbook does not provide any clear information about the counterfactual forms and meanings. The given information assumes that students already have knowledge about if-conditionals from lower level classes.

\subsubsection{No-overt conditionals.}

These constructions are used to state personal feelings or judgments without commitment to the said statement, rather than expressing negative implication or irrealis meaning. In the example of (21), epistemic would denotes present time (i.e. the judgments are made in the act of speaking) when used with a simple infinitive, be. As 
seen in (22), would is used with the perfect infinitive (have cared) to express conjecture about the past.

\section{Table 15.}

\section{Verb Form of No-overt Conditionals}

\begin{tabular}{|c|c|}
\hline Meaning & Form \\
\hline $\begin{array}{l}\text { Tentative prediction for pres } \\
\text { hypothetical possibility }\end{array}$ & $\begin{array}{l}\text { t(21) Predictably, this gazebo would be by Wren. } \\
{[\text { would }+V]}\end{array}$ \\
\hline $\begin{array}{l}\text { Tentative inference for past } \\
\text { hypothetical possibility }\end{array}$ & $\begin{array}{l}\text { (22) He would not have cared why it emerged, he only } \\
\text { wanted to capture a memory to play with it again in his } \\
\text { imagination... } \\
\quad[\text { would }+ \text { have }+V+-e n]\end{array}$ \\
\hline
\end{tabular}

Table 16 below shows how each textbook covers no-overt conditionals.

\section{Table 16.}

Focus on Form Techniques Found in No-overt Conditionals

\begin{tabular}{|c|c|c|c|c|c|}
\hline Textbook & IF & $\mathrm{IE}$ & $\mathrm{CR}$ & $\mathrm{EE}$ & Total \\
\hline KE1 & 4 & & & & 4 \\
\hline KE2 & 4 & & & & 4 \\
\hline KE3 & 3 & & & & 3 \\
\hline KE4 & 8 & & & & 8 \\
\hline KE5 & 1 & & & & 1 \\
\hline Total & 20 & 0 & 0 & 0 & 20 \\
\hline
\end{tabular}

As shown in table 16, no-overt conditionals were completely neglected in terms of Focus on Form, as they only occur in the input category of the Focus on Form techniques and only in small numbers. The forms of no-overt conditionals are neither visually emphasized nor presented in any activity that would consciously attract the attention of the learners. Two kinds of forms (would + infinitive and would + perfect form) in no-overt 
conditionals have unique meaning/function (e.g. used to avoid naked assertion regarding the verity of the comments about present or past events rather than to convey negative implications), but these are not presented with any explicit information. None of the textbooks clarify the distinction between epistemic and volitional polite use of would, which may lead students to inappropriately use these features. Also, no practice or activity regarding no-overt conditionals was found.

\subsubsection{Comparison between $\mathrm{CR}$ tasks and exercises.}

A total of twelve exercises were found for all types of conditionals. Ten of them were focused on if-conditionals. The types of exercises presented in the textbooks were: one matching task, five fill in the blank tasks, one substitution drill, and three rearrangement activities, all of which are isolated structure-oriented practices. Additionally, there were two exercises related to alternative conditionals that were also decontextualized form-centered practices. For example, one exercise was a substitution drill test where students convert generic noun-would co-text forms to if-conditions following the model examples. It is possible that students may just blindly follow the model examples to complete the task without noticing the relationship between the alternative conditionals and if conditionals. Thus, this exercise could be just a mechanical drill of switching form without understanding the structures and the meaning. Throughout all of the textbooks, exercises were much more common than CR tasks as shown in table 17 below. 


\section{Table 17.}

\section{Textbook Exercises and CR Tasks}

\begin{tabular}{lll}
\hline & Exercises & CR tasks \\
\hline If-conditionals & 10 & 1 \\
\hline Alternative conditionals & 2 & 0 \\
\hline No-overt conditionals & 0 & 0 \\
\hline
\end{tabular}

\subsubsection{Survey of activities used for hypothetical would-clauses.}

On the other hand, communicative activities that instruct students to pay attention to specific language features (three types of would-clause conditionals) were very rare. An activity found in KE3 leads students to use a language form relevant to certain communicative function (giving advice) while referring to the model conversation.

\section{Textbook Sample 9.}

Write down two goals for traveling and get advice from your classmates about which places to visit. Then choose the best place to go and explain why.

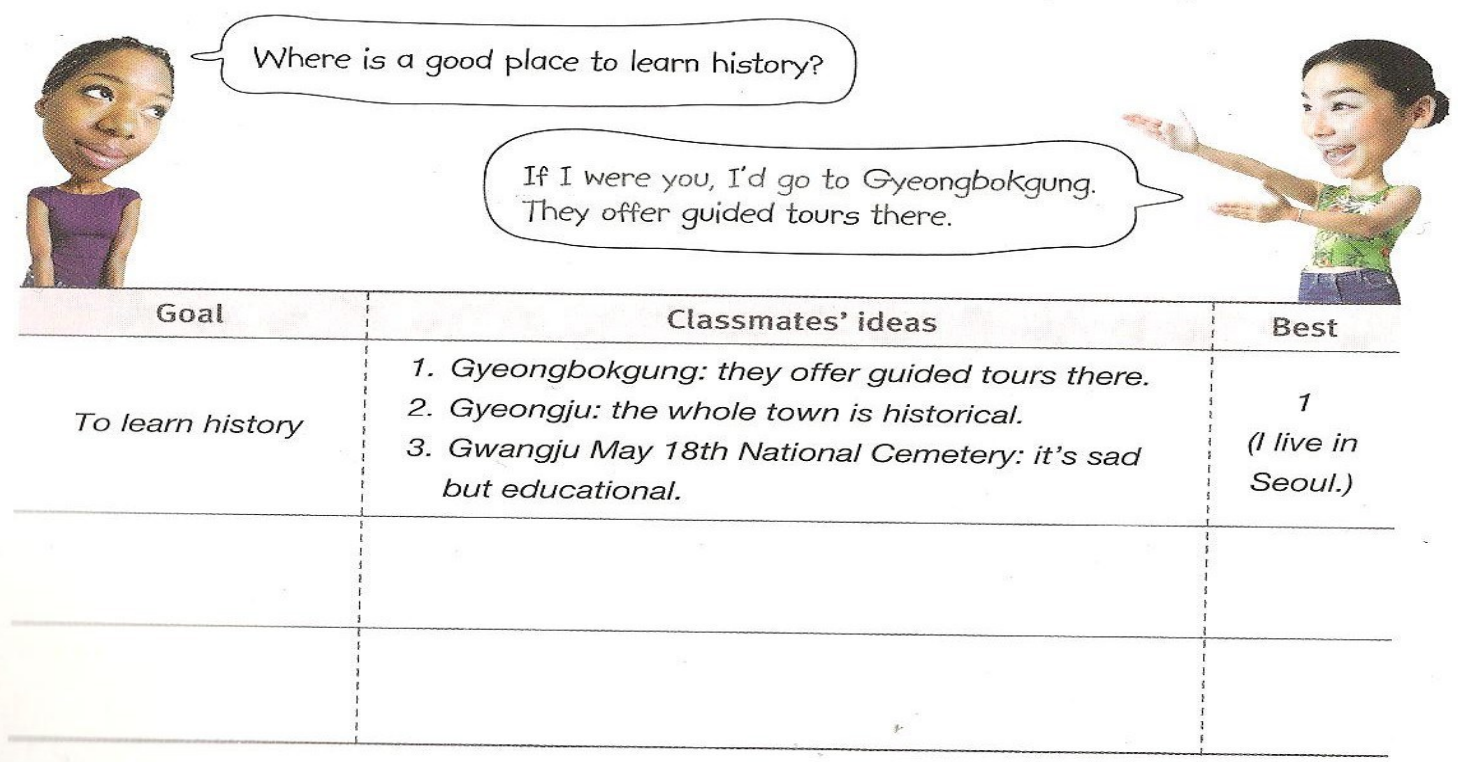

p. 33 in KE3) 
In this activity, learners would ideally use the target language form (present hypothetical, if I were you, I'd..) to perform the task. Although the language form suggested in this activity is idiomatic, the mechanism of this activity meets the intentions of Focus on Form as this activity can draw learners' attention to certain form while keeping them focused on communicative functions. However, most of the activities simply attempt to encourage students to communicate without directions necessarily to use the target language form.

In sum, the frequency comparison of different types of would-clauses in textbooks indicates that would clauses accompanying if-conditions are highly emphasized in Korea EFL textbooks, whereas alternative conditionals and no-overt conditionals are relatively overlooked. These frequencies do not reflect those occurring in real language use. The next analysis indicates that grammar patterns that commonly occur in naturallyoccurring language, such as grammatical co-text (alternative conditionals) and lexicogrammar (no-overt conditionals), are neglected in the textbooks. The last examinations show that textbooks fail to fully present the target language features in ways that draw learner's attention to form. Additionally, there was almost no activity that leads the learners to focus on the form while interacting with other learners. These issues will be further discussed in the following section. 


\section{Chapter 5: Discussion of the Results}

\subsection{Real Language Use: Frequency Comparison of would-Clause Varieties}

The results of the first research question show that Korean high school English textbooks hardly reflect the real use of conditionals as described in the Frazier's corpus study. While would-clauses accompanying if-conditions are highly emphasized in Korea EFL textbooks, would-clauses without if (alternative and no-overt conditionals) are much overlooked. The predominant use of would-clauses with if not only shows that the textbooks do not accurately reflect real life English usage but also that the textbooks are imbalanced in the coverage of different types of would- clauses. ${ }^{10}$ The results suggest that the textbooks were written by either the conventions of previous textbook writing or personal intuition of the textbook writers, which oftentimes may not reflect how language is used in real life contexts.

\subsection{Real Language Use: Grammar Patterns of Alternative Conditionals}

The next analysis indicates that grammar patterns that commonly occur in native English settings, such as grammatical co-text (alternative conditionals) and lexicogrammar (no-overt conditionals), are neglected in the textbooks. With respect to grammatical co-text, many of the textbooks do not use all of the patterns discussed by Frazier. There were also big frequency disparities between different types of co-text

\footnotetext{
${ }^{10}$ The textbooks' imbalanced coverage of hypothetical would-clauses is also shown in their treatment of no-overt conditionals that carry polite volitional meaning. Even though I excluded these tokens following Frazier's criteria, they occupied $55 \%$ of the total conditional frequency in the textbooks. It may seem that polite volitional would-clauses are commonly used in real life settings. However, when compared with other conditionals, the polite formulaic expressions seem overabundant in the textbooks, which may be due to the sentiment that these features are indispensable for students to gain pragmatic competence. There is an especially apparent disparity between the frequency of no-overt epistemic would-clauses and that of noovert polite volitional would-clauses.
} 
patterns. No token of infinitive construction was found. As previously mentioned, the lack of infinitives in the textbooks does not reflect empirical evidence that infinitives are often used to express hypotheticality or non-reality in conditional contexts (Duffley, 2006). While implied conditionals (Ø-would) were presented with the highest frequency (29 examples), the relatively high frequency of the pattern may be due to the natural tendency to avoid repetition of information implied in the context rather than it being deliberately incorporated.

Examples in the textbooks though do seem to occur in registers consistent to those in the corpus findings. They also show the function of each alternative structure as described by Frazier's corpus study. For example, generic noun-would patterns, the second most common feature in the textbooks (17 times), were all found in reading passages, a trend consistent with the corpus finding that generic noun-would patterns are common in written text. In KE4, one unit is set on generic-would co-text, so the textbook provides a relatively large number of examples of these features.

\section{Textbook Sample 10.}

On the contrary, the rise of broadcast media and information technology has brought about the emergence of a ridiculously simplistic and superficial political world- a world in which real political argumentation has been replaced by the soundbite. This is a reason to demand that voters be older, and wiser to the tricks of the media spin-doctor. An 18-year old voter would be putty in the hands of media managers. (p. 197 in KE4) 
The text above, as a part of a debate over the proposal that would lower the voting age in Korea to 18 , argues why the voting age should stay as it is. In the last sentence, the hypotheticality is carried by two components: indefinite article an and modified noun with non-real meaning (18-year old voter). As 18-year-old voters do not exist in Korea, the noun phrase itself implies a non-real condition. Conditionality of the noun phrase is supported by the hypothetical marker would. If the generic noun phrase is converted to an if-condition, the sentence would be, if an 18-year old voter were allowed to vote, he would be putty in the hands of media manager. Even though the two expressions carry the same meaning, the noun phrase (an 18-year old voter), while more condensed than its corresponding if-clause, still fully implies the conditional situation. KE4's intensive treatment of generic noun-would co-text patterns may allow students to become aware of the patterns.

However, the majority of the patterns are rarely or never treated in the textbooks. The gerund-would co-text patterns occurred only once in most of the textbooks. The following is a gerund token from KE2.

\section{Textbook Sample 11.}

In fact, small farmers produce four times as much food as big farmers per acre because they work much harder and use their land more efficiently. Taking a land from rich farmer and giving it to poor tenant farmer would greatly increase food production, as long as this was accompanied by low-interest loans with which to improve the land, information about better farming techniques and fair prices for crops. (p. 192 in KE2) 
While the gerund structure can be substituted by an if-clause such as if they (government) took a land from rich farmer and gave it to poor farmer, the pragmatic tone created by the if-clause differs from the original gerund constructions. The conditional marker if initiates hypothetical meaning and the verbs in the if-clause (took and gave) undergo backshift, denoting unreal meaning. Thus, if-clauses contain components that ignite the hypothesis and the consequent would also serves as the hypothetical marker. Similar effects can be observed when gerund structure is converted into to-infinitive, because the infinitive marker (To take..) also can be considered as "a trigger of hypothesis" (Duffley, 2006). On the other hand, in the gerund-would construction, the only hypothetical marker is the would construction itself, as Frazier stated. Thus, gerund-would co- text patterns imply a relatively lower level of hypotheticality than that of if-clauses or infinitive equivalents. In the example above, it seems that the writer shows strong opinion toward the probability of the event by using gerund structure. Despite such distinguishable pragmatic functions in the English language, gerund-would co-texts were almost entirely neglected in the textbooks. Thus, this pattern should be better represented in the textbooks.

The small number of tokens and huge variability between co-text patterns indicate that the co-text patterns of alternative conditionals may not have been considered as content that should be systematically incorporated into textbooks. Moreover, the textbooks' treatment of certain types of alternative conditionals (see p. 58 and 59) implies that the conditionals were written into the textbooks under the assumption that students already know about if-conditionals. Textbook examples and drills of alternative conditionals discuss how these types can be converted to if-conditionals. It seems that 
students are expected to easily learn alternative conditionals once they have learned prototypical if-conditionals. Alternatives are just considered as substitutes for ifconditionals. However, even though the functions of if-conditionals and alternative conditionals are similar to those of would clauses, they differ in terms of conditional forms, which may create distinct pragmatic values that should not be overlooked.

\subsection{Real Language Use: Grammar Patterns of No-overt Conditionals}

When would carries an epistemic meaning, the probability adverbials (perhaps and probably) and seem intensify the tentative tone. In the idiomatic expression it would seem, the corpula verb seem indexes the speaker's talk about his perception, not about the objective reality, while would add more distance to the commitment of the statement's factuality. Frazier mentions that the association occurs often in real language data. In addition, he also asserts that would structures were connected to the adverbial never whenever denial was expressed toward hypothetical possibilities in the corpus data.

In contrast to such corpus findings, the textbooks have very few instances of association between an epistemic would and words with a specific function. Especially, the collocation of would and seem did not occur even once in all of the five textbooks. Chen (2010), comparing the usage of epistemic modality between native speaker corpora and Chinese English learner corpora, suggested that the infrequent usage of epistemic modality that expresses uncertainty could be in some ways attributed to the different cultural perspective of NNS learners. He stated that "many Chinese people view certainty as a sign of strength and hedging as a sign of weakness" (p. 44). This cultural ideology could have been reflected in their L2 writing as well as their first language use. Even though this cultural view may not be completely generalizable to Korean contexts, the 
total lack of would seem examples in Korean textbooks does suggest that the textbook writers hardly use double hedges.

In addition to the cultural reasons, Hyland (1994)'s study gives an explanation for the rarity of epistemic modality in the EFL textbooks. He points out that that many English language teaching materials lack attention to modal verbs that carry epistemic meaning, which indicates that epistemic modality is not highly considered in English learning contexts. However, especially in academic contexts, having the ability to appropriately use epistemic modality may be important as it could indicate advanced levels of both linguistic and pragmatic proficiency. Many studies have pointed out that would, as an epistemic marker, is often used in written texts and academic settings such as lectures, science textbooks, and research articles (Frazier, 2003; Hyland, 1994; Camiciottoli, 2004; Vazquez and Giner, 2008). In the following paragraph, I note common usages of epistemic use of would that go largely ignored in the textbooks.

In the lexical association of would constructions, the idiomatic phrases would seem are especially common in newspaper articles. Frazier's corpus study informs us that would is often connected to the state verb seem and function as strategic hedges that amplifies the tentativeness of the state verbs. In a Washington Post politics column, the writer, when describing Mitt Romney's stance toward enhanced interrogation techniques, says that "it would seem that Romney is implicitly saying he would overturn [Obama's] executive order" that limits interrogation techniques to ones found in the army field manual. Because Romney at the time did not explicitly say whether he would overturn the executive order, the columnist uses the compound hedge, would seem to express little degree of commitment to the truth of his statement and avoid any possible controversies. 
This attempt to distance himself from the facticity of the statement becomes further overt by the use of the adverbial "implicitly," which was also emphasized in italics by the writer.

The epistemic use of would is often found in works of academic research. The following example is one that does not appear within a lexico-grammar pattern but still shows how would is used as a hedge in a research paper. A researcher writes on his paper that "because on the top of the loop the rod would have too high a curvature. This would lead to an overlap at the top of the loop, as can be seen in Figure 3"(Vazquez and Giner, 2008, p. 183). In this short passage, the writer uses would twice to add tentativeness to his explanation of the shapes. Writers of academic writing often try to keep the distance between their written arguments and their personal liability to their writing to mitigate possible heavy opposition.

As discussed, different cultural views and/or English materials' general inattention to epistemic modality may partially explain the lack of lexical associations showing the pragmatic usage of epistemic would in the Korean EFL textbooks, despite its useful applications in various real life situations. Consequently, Korean EFL learners seem to have little opportunity for exposure to epistemic would clauses and their lexicogrammar patterns, as the present study clearly shows.

\subsection{Focus on Form: Implicit vs. Explicit Method \& No Presence of Output-oriented Focus on Form}

Although the examination with respect to Focus on Form shows different results per each conditional, in general, implicit methods (input flood and input enhancement) were more common than explicit methods (consciousness raising task and explicit 
explanation). In all types of conditionals, input flood (IF) show a higher frequency than those of other techniques. If-conditionals, particularly, occurred with a total of 136 tokens of input and showed the highest frequency. However, this extremely implicit technique may lack salience for getting learners' attention. Some researchers point that input flood by itself is too implicit, and its lone use may not be particularly effective (Doughty and Williams, 1998; White, 1998). Moreover, the amount of input of alternative and no-overt conditionals may be inadequate for the form to be noticed.

Typographical manipulation of the forms (IE) occurs in if-conditionals with a total of 15 . Although not very numerous, the tokens appear consistently in four out of five textbooks. On the other hand, this technique was very infrequent in alternative and no-overt conditionals. There are inconsistent opinions between studies regarding the effectiveness of input enhancement. Jourdenais et al's study about Spanish verb forms indicates a positive outcome about this technique (Doughty and Williams, 1998). However, White (1998)'s study on the acquisition of third person possessive determiners shows no meaningful advantages of typographical enhancement. White believes that the students' attention may not have been drawn to the target forms as much as he had anticipated. To obtain a bigger benefit from this implicit method, he suggests, a more explicit type of enhancement should be supplemented, such as the use of arrows that can clarify the relationship between the possessive determiner and its referent.

Among all of the conditionals, explicit methods (CR and EE) were almost nonexistent. Consciousness-raising tasks, which direct learner's attention to form, occurred only once for if-conditionals. Several studies (e.g. Fotos and Ellis, 1991; Fotos, 1993) assert the efficacy of CR tasks in enhancing the grammatical knowledge and 
learners' noticing (Ansarin and Arasteh, 2012). CR tasks are similar to traditional exercises in that both isolate a specific linguistic feature for focused attention. However, Ellis distinguishes CR tasks from exercises by arguing that "whereas practice is primarily behavioral, CR is essentially concept forming in orientation" (2002, p. 169). In other words, while exercises focus on the correct production of the target features and emphasize repetition, CR tasks put more weight on the process in which students make efforts to understand the target features based on given data. Then, it should be noted that when compared to traditional grammar exercises and drills, CR tasks still appear much less frequently in the textbooks.

Additionally, explicit explanations, which may be important for clearly understanding the features, are not presented in any meaningful amount. Especially, the explicit explanations for if-conditionals were merely brief references without any metalinguistic information. It is noted that while if-conditionals are much more frequent than any other conditional types in terms of implicit method(IF and IE), its frequency differed little when compared to that of other types in terms of explicit explanation. It seems that students are expected to implicitly understand and use the conditional forms and functions. Importantly, the textbooks almost neglect past counterfactual conditionals, indicating that student are somehow expected to understand and use the form and meaning by relying on a handful of examples and implicit contextual information. The positive effects of explicit instruction (e.g. metalinguistic explanation and corrective feedback) have been shown in considerably numerous studies (DeKeyser, 1995; Alanen, 1995; Robinson, 1996; Muranoi, 2000; Norris and Ortega, 2000, etc.). Researchers who emphasize the positive aspects of explicit instruction argue that though explicit 
knowledge does not directly alter a learner's interlanguage form, it could develop learner awareness of the target form and help them produce useful input to his or her system (Lightbown, 1998). In other words, when the learner's attention to the target form is drawn with an explicit instruction, learners are more likely to notice the target form in future inputs, which can facilitate the eventual acquisition of these forms as implicit knowledge (Noonan, 2004). This is especially applicable to EFL contexts, where the amount of the possible target language input is limited.

In sum, as for alternative and no-overt conditionals, the textbooks provide very few instances of both implicit and explicit Focus on Form techniques. It is difficult to say that the miniscule number of techniques would be able to attract or direct learner attention. Concerning if-conditionals, as was predicted in the frequency comparison in advance, the EFL textbooks are generally much more concerned about these features than other types of conditionals. Korean EFL textbooks seem to concentrate on them more than other types of conditionals by providing high frequency of input. However, in terms of explicit explanation, its frequency of if-conditionals is not different from that of other types, as they are all rare in that respect. In addition, most of the textbooks carry a certain number of exercises while there is one textbook that contains a CR task and it is only one. This shows that even though the exercises in the Korean EFL textbooks especially focused on if-conditionals, the language features are not well-represented when viewed in terms of the Focus on Form approach. It seems that Korean EFL textbooks in general fail to present the target language features in ways that draw learner attention to form as recommended by the Focus on Form approach. 
More importantly, the examination made it clear that textbooks hardly present the would-clause conditionals in ways that draw leaner attention to form but are not isolated from communication. Only KE3 provides a communicative activity that enables learners to use the target language features while keeping them focused on communication. Other communicative activities do not explicitly lead students to use the target form. The results indicate that even though the Korean national curriculum recommends focus on form as a way to develop both grammatical accuracy and communicative fluency, the textbooks hardly present activities to meet this goal. Poole (2005) points out some constraints that would make the implementation of Focus on Form in EFL especially difficult, two of which were especially applicable for Korean EFL contexts. The first is that many nativeKorean EFL teachers lack high levels of oral English proficiency to give reactive feedbacks, and the second, that the classroom sizes are too large for teachers to pay attention to problematic forms of individual students. These issues are relevant to the role of the teachers. Under a structural curriculum, teachers usually control the whole class lesson, whereas, in an entirely meaning-centered curriculum, teachers are regarded as "a facilitator or monitor," (Richards, 2006) and exercise minimized pedagogical intervention. On the other hand, in a Focus on Form approach, a teacher's role becomes more versatile, switching between facilitator and controller. Teachers not only assist learners to participate in communicative activities but also give them corrective feedback as a pedagogical interrupter. Taking Poole's constraints into account, an ideal Focus on Form instruction as first suggested by Long (1991) is not likely to be realized soon in Korean EFL education, because such instruction would require teachers to have at least nearnative fluency for shifting learner attention to linguistic elements that could incidentally 
arise. However, preplanned Focus on Form instruction, as a proactive attempt to communicatively teach certain linguistic forms, seems to be a feasible alternative for Korean English classrooms. With preplanned Focus on Form activities incorporated into textbooks, teachers who may not be very fluent would have a good idea of what they would instruct during the activity beforehand. In addition, large classroom sizes would not cause much hindrance in such activities. 


\section{Chapter 6: Conclusion}

This study examined five Korean high school English textbooks based on two topics: real language use and Focus on Form as presentation method. These examinations aimed to see if textbook descriptions reflect real language use and present the target features in ways that draw learner attention to form. This chapter presents a summary of the findings, implications, limitations of the study, and some ideas for further studies.

\subsection{Summary of the Findings}

In this study, I first investigated the degree to which the target language features of the textbooks are consistent with the corpus findings in terms of their frequency and grammar patterns. For each examination, I compared textbook descriptions with Frazier (2003)'s corpus findings.

In the frequency examination, the result showed that conditionals with if are more prevalent than the other two conditionals without if by a ratio of 3: 2 . This outcome was not consistent with the corpus study findings, which suggested that conditionals without if (alternative and no-overt conditionals) occupy $74 \%$ of hypothetical would-clauses in real language use. Especially, while alternative conditionals take up approximately $60 \%$ of conditionals in the corpus study, if conditionals instead are emphasized much more in the textbooks. Although alternative conditionals are much more commonly used than if conditionals (60\% to $25 \%)$ in authentic language contexts, the Korean EFL textbooks mainly emphasized if conditionals.

After comparing different types of would-conditionals, I examined alternative and no-overt conditionals to identify the extent to which they reflect real grammar patterns shown in Frazier's corpus study. In the textbooks, grammatical co-text patterns of 
alternative conditionals rarely reflect the findings from the corpus study in terms of diversity. Especially, I could not find any token of infinitive-would pattern across the textbooks despite the patterns' frequent usage in naturally occurring language (Duffley, 2006). Also, typical lexico-grammar patterns in no-overt conditionals seldom occur in the textbooks. In this study, no token about the collocation of would and seem was found, even though this is often used in written contexts. The textbook languages examined in this study hardly reflect the patterns of the language features that commonly occur in genuine texts.

The second research question was about whether the hypothetical would-clauses are presented in a way that draws learner attention to form as recommended by the Focus on Form approach. Regarding the extent to which Focus on Form techniques were used to draw learners' attention to the form, while input flood was more common than any other technique, explicit techniques (CR and EE) occurred rarely, if ever. Moreover, with respect to alternative and no-overt conditionals, the amount of input provided may not be enough for students to become aware of the conditional form. As for the activities targeting output production, I found two types. One type shows little or no deviation from isolated structure-centered exercises, which are commonly found in traditional grammar teaching. The other types of activities simply attempt to enhance communication without focused attention toward the target features, which are often used in communicative language teaching. Thus, almost none of the textbooks provided activities that can draw learners' attention to form while keeping them focusing on communication as suggested by the Focus on Form approach. 
The English curriculum in Korea, which has gone through many reforms in search of providing an effective English education, has recently adopted two innovative amendments: authentic language use and Focus on Form. For EFL learners who have limited access to real language input, school textbooks are the primary sources for language patterns and usage. The findings from this study indicate that textbook descriptions do not adequately reflect the real language use of would-clauses. In addition, while the current curriculum strongly recommends publishers to put out textbooks that utilize the Focus on Form approach for a balanced language development, it is difficult to say that there has been a consistent attempt to attract (implicitly) or direct (explicitly) the learners' attention to form and encourage them to use the target form in the context of meaningful communication as advocated by the Focus on Form approach (Doughty and Williams, 1998).

\subsection{Implications}

The findings suggest that the textbooks take little account of the two issues raised in this study which are 1) empirical evidence is a more valuable source for textbook writing than writers' personal intuition of the language use and 2) the way in which language features are presented is an important factor for optimizing learning. The implications are discussed based on these two issues.

\subsubsection{Implication of real language use.}

With increasing use of English, the interest in incorporating authentic language into English textbooks has been growing in Korean EFL contexts, and the 2006 reform policy encourages the use of real language in classroom settings. Textbook vocabulary has already been heavily influenced by corpus data. However, the results of this study 
show that textbooks are seldom supplemented by corpus information especially with respect to hypothetical would-clauses. Although alternative conditionals occupy a significant portion of naturally occurring language, the textbook writers seemed not to have taken this statistics into account and instead presented most of the would-clauses in co-text forms with if-conditions. Also, no-overt conditionals that carry epistemic meaning tend to be overlooked in the textbooks despite its considerable use in authentic language; consequently, the functions that are associated with particular contextual uses were also neglected (e.g. hedging markers of epistemic would are often used in lectures and research articles).

One may ask why the aforementioned features matter in EFL education. Some scholars such as Prodromou (1996) and Cook (1998) have raised doubts as to whether language use in native speaker communities should be a model for learners of English as an international language. They specifically targeted "culture-loaded language" (Cook, p. 60) to question whether EFL learners really need to learn such language. This issue reminds me of Korean EFL textbooks' total lack of presentation of the double hedging and also of Chen (2010)'s study, which related Chinese learners' rare use of hedging markers to their L1 cultural values. Hedging markers, though commonly and widely used by native English speakers, are English culture-specific to Chinese or Korean EFL learners. However, language in general is culture-loaded and language communityspecific; learning a language is acquiring not only linguistic competence but also its use in the cultural and social context that is reflected by the language. For EFL learners, a corpus can provide information about the wide usage of such culturally embedded 
language (hedging markers). There seems to be no reason for the learners not to learn that kind of language.

In addition, as Carter (1998) noted, non-native speakers also have a real need to interact in the target language. ${ }^{11}$ For a long time, English education in Korea has largely been a way of differentiating academic performance levels of high school students in standardized exams. However, as a consequence of the increased use of English, many graduating students are increasingly required to utilize their knowledge of English in real life contexts where understanding correct nuances of the language and delivering expressions in appropriate ways may be important. This is applicable to many possible situations, such as when trying to understand a complex and subtle concept during lectures in English, reacting to a deal worded in intricate and subtle language during a business negotiation with native English speakers, reading between the lines in written texts, or writing research articles. While the target language features in this study, modal verbs (would) are widely used for "expressing attitudes and evaluate and comment" (Carter, p. 50), it would be difficult for non-native speakers to use these features with correct nuance in oral and written communication. In that respect, Frazier's corpus-based study shows how would constructions are used in real communicative contexts (e.g. would is often used during college lectures as hedging markers and for describing imaginary concepts - see footnote in p. 11). Also, the ways in which no-overt conditionals are utilized in written texts have already been illustrated in the discussion section. These examples may allow non-native speakers to realize the gap between native

\footnotetext{
${ }^{11}$ In an EFL context like Korea, English communication between Korean and English native speakers is much more frequent than between non-native speakers of English.
} 
English settings and EFL language materials in using certain language features (would), and suggest how to use the language features in particular settings.

Cook (1998) argues that frequency of real language data does not always indicate the value of language. While frequency should not be the only determinant, it would be the role of textbook writers, especially textbook writers in EFL contexts, when designing textbooks with consideration of frequency information, to discern what is applicable for the learners for proper use of English. The Korean senior high school English textbooks maintain the pursuit of both interpersonal communicative skills and cognitive academic language proficiency. As mentioned, would constructions are widely used in both communicative and academic settings as hypothetical and hedging markers. The appropriate uses of modal verbs (e.g. would), therefore, may be critical for students in attaining both communicative and cognitive competence of English language.

The information from corpus findings indicates to textbook writers that approaches to language based on personal intuition or the author's perception of conventional use may not always be equivalent to real-life patterns. In this regard, this study suggests that the curriculum writers should consider using real language data to determine what grammar patterns to teach and to what extent these patterns will be covered.

\subsubsection{Implication of teaching approach (Focus on Form).}

The other concern of this study was in the facilitation of the learning of form, meaning, and function of the aforementioned features. One important function of a textbook is to help learners use language features in accurate and appropriate manners. In terms of accuracy, drawing learners' attention to the target form should not be neglected 
since conditionals are realized by different grammatical structures and would-clauses denote unreality and time reference in various forms. Also, semantic or pragmatic information should be given for appropriate use. Unfortunately, the results of this study indicate that the current textbooks may be unable to draw learners' attention to form and address the meaning or functions. Moreover, there were very few integrated tasks that attempt to draw learners' attention to linguistic elements in the context of performing communicative activities, which could enhance the noticing of form-meaning-function relationship.

In this regard, I made some suggestions and applications for the target language features in terms of the two modes of Focus on Form (input and output based) approach. Particularly, for the application of Focus on Form task, I suggest preplanned types of Focus on Form (CR task and dictogloss), as they allow for the design of structured input (Barbieri and Eckhardt, 2007), which makes it feasible for the incorporation of corpusbased grammar in textbook writing. Additionally the texts used for model tasks were excerpted from several sources of naturally-occurring language, which would deliver authentic contexts that students may find useful when applying their learning of the target language features to real life uses.

\subsubsection{Application for input based Focus on Form (implicit to explicit).}

The Focus on Form techniques utilized in the textbooks are all input based and located at the ends of implicit and explicit continuum. Input flood (IF) and input enhancement (IE) are implicit techniques that attract leaners' attention without any metalinguistic discussion while consciousness-raising task (CR) and explicit explanation (EE) are explicit techniques that direct learners' attention and exploit grammar 
instructions. The textbook examination showed that IF (or merely input) was the most common technique and IE was the next most common, while CR and EE were almost nonexistent.

Although the textbooks provide input of the target features, it is dubious whether students are likely to meaningfully benefit from this extremely implicit method, especially in EFL contexts where language input is limited, such as Korea. Thus, textbooks should present the language features in a more salient manner that further draws learners' attention to form. This may be achieved by including a larger variety of visually explicit input enhancements. White (1998) asserted that providing more explicit type of enhancement, preferentially along with explicit explanation, can increase student's awareness of the form. In addition, as textbooks are often the only available source of direct approach for language features, functional information should not be neglected. In the textbooks, for example, gerunds are presented in a minute number of examples. In this case, it may be difficult for students to understand and use the form and function just by reading the text. Here is an example of such gerund structure in KE5.

\section{Textbook Sample 12.}

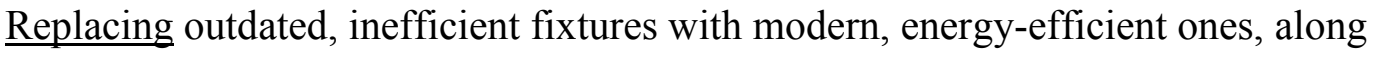
with installing buildings with more motion-sensors and timers, would certainly help to save energy and reduce the amount of light wasted. (p. 121 in KE5)

In the example above, there would be no propositional meaning difference if the gerund construction is converted to an infinitive or an if-condition. Nevertheless, the use of gerund allows the speaker to express a stronger position in terms of the probability of an 
event occurring. Moreover, the use of the adverbial certainly strengthens the reified meaning of the gerund structure. On the other hand, infinitives are often used to express more concessive and hypothetical opinions. However, students may not notice the subtle difference of usage between gerunds and infinitives with just input. Explicit information along with typographically enhanced input could help students better recognize the appropriate context to use either gerunds or infinitives. For example, students may benefit from the information presented in table 7 and 9 (see p. 50 and 53) regarding the forms and functions of the two types of conditionals. Therefore, in addition to providing implicit techniques (a variety of enhancement that are easily noticed by students), textbooks should also provide explicit instruction of linguistic and pragmatic information for accurate and appropriate use of the language.

One last suggestion regarding input-based Focus on Form techniques is to increase the number of consciousness-raising tasks, which are almost nonexistent in the textbooks currently. As an input-based explicit task, a CR task does not encourage students to produce the target form immediately. Instead, it aims to raise learners' consciousness of the target features by directing them to analyze the data with the features and leading them to "utilize their intellectual effort to understand the target features" (Ellis, 2002, p. 168). In addition, even though the CR task presented in the EFL textbook does not direct learners to discuss the language features, through metatalk, it enables students to pay attention to form in the communicative contexts. In this regard, I designed a task for raising consciousness toward the form and meaning of perfect forms of infinitive-would co texts (alternative conditionals) and those of no-overt conditionals (see Appendix A). In this activity, learners are expected to notice the textually enhanced 
target features in the given data, to make intellectual efforts to understand the form and meaning of the features, and to achieve an explicit understanding of the target features through further data. These characteristics are consistent to those of CR tasks defined by Ellis (2002). The questions included in the task may "require learners to consciously analyze data in order to arrive at an explicit representation of the target features," as Ellis and Fotos (1999, p. 192-193) maintain.

\subsubsection{Application for output activity: integration of form and meaning focus.}

The aforementioned IF, IE, CR and EE have little to do with the actual production of the target language features. Accurate and appropriate production of the target language features could be catalyzed by integrated tasks that increase students' attention to form while keeping them engaged in communication. As mentioned before, however, most of the activities in the textbooks are either decontextualized drills or communicative tasks that do not attempt to encourage students to use the specific grammar forms.

According to the basic tenets of Focus on Form, language forms should be presented in meaningful contexts so that learners can develop their communicative ability in terms of both accuracy and fluency. Doughty and Williams (1998) discuss a variety of Focus on Form tasks that can draw learners' attention to form while developing communicative skills simultaneously. One of the output-based techniques, dictogloss, in which production of target form is highly likely to occur, provides meaningful communicative contexts that can raise learners' awareness of the target language features during discourse. This task directs learners to discuss the language that they are reconstructing, which may lead them to notice that they cannot say what they want to say precisely in the target language and eventually notice the holes in their inter-language 
(Swine, 1998; Doughty \& Williams, 1998). Furthermore, the metatalk may trigger learners to move from semantic to syntactic processing, which is necessary for attaining fully accurate target form. In this regard, I created a dictogloss task which aims to draw learner's attention to form during collaborative work (see Appendix B). The text was excerpted from Weisman's “The World Without Us.” The text includes hypothetical would-clauses in almost every sentence because it describes the hypothetical consequences that could occur if humanity were to suddenly disappear completely. This activity may draw students' attention to the three aspects of grammar: form, meaning, and use.

The suggested sample activities only show a limited variety of tasks regarding real language use and Focus on Form apporoach. Textbook writers could use real language sources of specific genres (written or spoken) in accordance with the corpus findings of the target language features and cover a greater variety of Focus on Form tasks.

\subsection{Limitation and Future Study}

A limitation of this study is that the results of Frazier's research were fundamental to this study although his data has not been reproduced by another researcher. This suggests that if the validity of Frazier's data is put into question, the analysis and interpretation of the present study would also be heavily affected and require major revisions.

Additionally, only percentage comparisons between the textbooks and the corpus findings were done in this study. However, one could have done statistical analysis with 
raw numbers, which could have shown whether the difference between the findings from the textbooks and the corpus data was statistically significant.

Lastly, this study only examined would constructions instead of collectively looking into all secondary modals. Secondary modals (e.g. would, could, might-clauses) share common semantic features such as an index of hypothesis, temporal reference, formality, politeness and tentativeness (Perkins, 1982). However, empirical evidence regarding their frequency in naturally occurring language was available for only wouldclauses and it would have been difficult to generalize corpus results about would-clauses onto other secondary modals. Further studies on the rest of the secondary modals could help bring more accurate insight into the presentation of all secondary modals in terms of form and function in Korean EFL textbooks.

This paper is primarily concerned with a specific grammatical feature (hypothetical would -clauses) with respect to the two issues raised in this study. However, it is also related to the more general issue of incorporating grammar use uncovered from corpora to pedagogical contexts and finding effective methods for teaching such language features. Corpus studies of grammar may give some insights for textbook writing by providing information of grammar patterns based on empirically validated data. In addition, Focus on Form may be instrumental for balanced learning of such grammatical features by focusing on both form and meaning. Grammar instruction should assist students in using empirically validated grammatical features in accurate and appropriate manner. In this regard, I call for future Korean EFL textbooks to incorporate commonly used real life grammar patterns and to adopt a more thorough application of Focus on 
Form (e.g. more explicit, output-based) as a way to effectively convey those grammatical features to students. 


\section{References}

Alanen, R. (1995). Input enhancement and rule presentation in second language acquisition. In R. Schmidt (Ed.), Attention and awareness in foreign language learning (pp. 259-302). Honolulu: University of Hawaii Press.

Ansarin, A. and Arasteh, B. (2012). Effectiveness of Consciousness-Raising in Acquisition of English Dative Alternation. Vigo International Journal of Applied Linguistics, 9, 9-38.

Babieri, F. and Eckhardt, S. (2007). Applying corpus-based findings to form-focused instruction: The case of reported speech. Language Teaching Research, 11, 319346.

Biber, D. \& Reppen, R. (2002). What does frequency have to do with grammar teaching? Studies on Second Language Acquisition, 24, 199-208.

Bolinger, D. (1968). Entailment and the meaning of structures. Glossa, 2, 119-127.

Camiciottoli, B. C. (2004). Modal verbs in cross-cultural business lectures. In R. Facchinetti \& F. Palmer (Eds.), English modality in perspective (pp. 27-44). Frankfurt: Peter Lang.

Carter, R. (1998). Orders of reality: CANCODE, communication, and culture. ELT Journal, 52, 43-55.

Celce-Murcia, M. and Larsen-Freeman, D. (1999). The grammar book: An ESL/EFL teacher's course ( $2^{\text {nd }} E d$.). Boston, MA: Heinle \& Heinle.

Chen, H. (2010). Contrastive learner corpus analysis of epistemic modality and interlanguage pragmatic competence in L2. Arizona Working Papers in SLA \& Teaching, 17, 27-51.

Conrad, S. (1999). The importance of corpus-based research for language teachers. System, 27, 1-18.

Conrad, S. (2000). Will corpus revolutionize grammar teaching in the $21^{\text {st }}$ century? TESOL Quarterly, 34, 548-560.

Conrad, S. (2010). What can a corpus tell us about grammar? In A. O'Keefee \& M. McCarthy (Eds.), The Routledge handbook of corpus linguistics (pp. 1-15). Milton Park, UK: Routledge.

Cook, G. (1998). The uses of reality: A reply to Ronald Carter. ELT Journal, 52, 57-63.

DeKeyser, R. (1995). Learning second language grammar rules: An experiment with a miniature linguistic system. Studies in Second Language Acquisition, 17, 379-410.

Doughty, C. (1991). Second language instruction does make a difference: Evidence from an empirical study of SL relativization. Studies in Second Language Acquisition, 13, 431-469.

Doughty, C. and Williams, J. (1998). Pedagogical choices in focus on form. In C. Doughty \& J. Williams (Eds.), Focus on form in classroom second language acquisition (pp.197-261). Cambridge, UK: Cambridge University Press.

Duffley, P. J. (2006). The English gerund-participle: A comparison with the infinitive. New York, NY: Peter Lang.

Ellis, R. (1994). The study of second language acquisition. Oxford, UK: Oxford University Press.

Ellis, R. (2002). Grammar teaching, practice or consciousness-raising?” In J. C. 
Richards \& W. A. Renandya (Eds.), Methodology in language teaching: an anthology of current practice (pp. 167-174). Cambridge, UK: Cambridge University Press.

Ellis, R. (2003). Task-based language learning and teaching. Oxford: Oxford University Press.

Ellis, R. (2010). Explicit form-focused instruction and second language acquisition. In B. Spolsky \& F. M. Hult (Eds.), The handbook of educational linguistics (pp. 437455). The Atrium, UK: Blackwell Publishing.

Ellis, R. and Fotos, S. (1999). Communicating about grammar. In R. Ellis (Ed.), Learning a second language through interaction (pp.189-208). Amsterdam: John Benjamin Publishing.

Frazier, S. (2003). A corpus analysis of would-clauses without adjacent if-clauses. TESOL Quarterly, 37, 443-466.

Gascoigne, C. (2001). Focusing on the future of grammar instruction: Focusing on form. Encuentro Revista de investigación e innovación en la clase de idiomas, 12, 67-74.

Gavioli, L. (2001). The learner as researcher: introducing corpus concordancing in the classroom. In Aston (Ed.), Learning with corpora (pp. 108-137). Houston, TX: Athelstan.

Gor, K. and Chernigoskaya, T. (2005). Formal instruction and the acquisition of verbal morphology. In A. Hausen \& M. Pierrard (Eds.), Investigations in instructed second language acquisition (pp. 131-164). Berlin: Mouton De Gruyter.

Haiman, J. (1986). Constraints on the form and meaning of the protasis. In E. Traugott, A. Meulen, J. Reilly \& C. Ferguson (Eds.), On conditionals (pp. 215-228). Cambridge,UK: Cambridge University Press.

Hunston, S. (2005). Corpora in applied linguistics. Cambridge, UK: Cambridge University Press.

Hyland, K. (1994). Hedging in academic writing and EAP textbooks. English for Specific Purposes, 13, 239-256.

Johns, T. (1991). Should you be persuaded: two samples of data-driven learning materials. ELR Journal, 4, 1-16.

Keck, C., Iberri-Shea, G., Tracy-Ventura, N. \& Wa-Mbaleka, S. (2006). Investigating the empirical link between task-based interaction and acquisition : A quantitative meta-analysis. In J. Norris \& L. Ortega (Eds.), Synthesizing research on language learning and teaching (pp. 91-132). Philadelphia, PA: John Benjamins.

Kennedy, G. (1998). An introduction to corpus linguistics. London, UK: Longman.

Krashen, S. D. (1982). Principles and practice in second language acquisition. Oxford, UK: Pergamon Press.

Lee, Mi- sun. (2010, March 29). Nyengyule Education's High School English Textbooks: Most Chosen for Seven Straight Years. The Korea Herald. Retrieved from http://biz.heraldm.com

Leech, G. (1987). Meaning and the English verb. London, UK: Longman.

Leech, G. (2004). Meaning and the English verb. London, UK: Longman.

Lightbown, P. (1998). The importance of timing in focus on form. In C. Doughty \& J. Williams (Eds.), Focus on form in classroom second language acquisition (pp. 177- 196). Cambridge, UK: Cambridge University Press. 
Long, M. (1991). Focus on form: a design feature in language teaching methodology. In K. de Bot, D. Coste, C. Kramsch \& R. Ginsberg (Eds.), Foreign language research in a crosscultural perspective (pp. 39-52). Amsterdam: John Benjamins. Lyons, J. (1977). Semantics. Cambridge, UK: Cambridge University Press.

Marr, C. (1990). Infinitive complement clauses in English: A study of syntax of discourse. Cambridge, UK: Cambridge University Press.

MEST (Ministry of Education of Science and Technology) (2012, March, 21). Commentary on the High School Curriculum (English). Retrieved March 21, 2012 from the World Wide Web: http:/www.english.go.kr/ebs

Millard, D. (2000). Form-focused instruction in communicative language teaching: implication for grammar textbooks. TESL Canada Journal, 18, 47-57.

Muranoi, H. (2000). Focus on form through interaction enhancement: Integrating formal instruction into a communicative task in EFL classrooms. Language Learning, 50, 617-673.

Nguyen, T., Pham, T. \& Pham, M. (2012). The relative effects of explicit and implicit focus on form instruction on the development of L2 pragmatic competence. Journal of Pragmatics, 44, 416-434.

Noonan, F, J. (2004, July). Teaching ESL Students to "Notice" Grammar. The Internet TESL Journal, 10. Retrieved December 21, 2012 from the World Wide Web: http://iteslj.org/Techniques/Noonan-Noticing.html

Norris, J. and Ortega, L. (2000). Effectiveness of L2 instruction: A research synthesis and quantitative meta-analysis. Language Learning, 50, 417-528.

Norris, R. (2003). How Do We Overcome the Difficulties of Teaching Conditionals? Bulletin of Fukuoka International University, 9, 39-50.

O'Keeffe, A. and Farr, F. (2003). Using language corpora in language teacher education: Pedagogic, linguistic and cultural insights. TESOL Quarterly, 37, 389-418.

Palmer, F. (1990). Modality and English modals. New York, NY: Longman.

Perkins, M. (1982). The core meaning of the English modals. Journal of Linguistics, 18, 245- 274.

Perry, F. L. (2005). Research in applied linguistics. New York, NY: Routledge.

Prodromou, L. (1996). Correspondence. ELT Journal, 51, 88-89.

Poole, A. (2005). Focus on form instruction: Foundations, applications, and criticisms. The Reading Matrix, 5, 47-56.

Quirk, R., Greenbaum, S., Leech. G. \& J, Svartvik. (1985). A comprehensive grammar of the English language. London, UK: Longman.

Richards, J. (2006). Communicative language teaching today. Cambridge, UK: Cambridge University Press.

Robinson, P. (1996). Learning simple and complex second language rules under implicit, incidental, rule-search and instructed condition. Studies in Second Language Acquisition, 18, 27-68.

Shin, D. and Nation, P. (2008). Beyond single words: The most frequent collocations in spoken English. ELT Journal, 62, 339-348.

Spada, N. (1997). Form-focused instruction and second language acquisition: A review of classroom and laboratory research. Language Teaching, 30, 73-87. 
Swain, M. (1985). Communicative competence: some roles of comprehensible input and comprehensible output in its development. In S. Gass \& C. Madden (Eds.), Input in second language acquisition (pp. 235-253). Rowley, MA: Newbury House.

Swain, M. (1998). Focus on form through conscious reflection. In C. Doughty \& J. Williams (Eds.), Focus on form in classroom second language acquisition (pp. 64-81). Cambridge, UK: Cambridge University Press.

Van der Auwera, J. (1986). Conditionals and speech acts. In E. Traugott, A.Meulen, J. Reilly \& C. Ferguson (Eds.), On conditionals (pp. 180- 197). Cambridge, UK: Cambridge University Press.

Vazquez, I. and Giner, D. (2008). Beyond mood and modality: Epistemic modality markers as hedges in research articles. Revista alicantina de estudios imgleses, 21, 171-190.

Widdowson, H. (1978). Teaching language as communication. Oxford, UK: Oxford University Press.

White, J. (1998). Getting the learners' attention: a typographical input enhancement study. In C. Doughty \& J. Williams (Eds.), Focus on form in classroom second language acquisition (pp. 85-113). Cambridge, UK: Cambridge University Press.

Zorzi, D. (2001). The pedagogic use of spoken corpora: Learning discourse markers in Italian. In Aston (Ed.), Leaning with corpora (pp. 85-107). Houston, TX:

Athelstan. 


\section{Appendix A Supplementary Activity 1: Consciousness raising task}

Form pairs and then discuss the given questions.

\section{Text 1}

Cosmic impacts that once bombed Mars might have sent temperatures skyrocketing on the Red Planet in ancient times, enough to set warming of the surface on a runaway course, researchers say. The origin of these immense craters roughly coincides with when many branching Martian river valley networks apparently formed. The impact that created Argyre basin would have released an extraordinary amount of energy, far more than any bomb made by humanity, or even the asteroid suspected of ending the Age of Dinosaurs 65 million years ago. It would have been an explosion with an energy on the order of $10^{\wedge} 26$ joules, or 100 billion megatons of TNT. Altogether, scientists had calculated these giant collisions would have raised surface temperatures on Mars by hundreds of degrees. (Excerpted from msnbc.com)

\section{Text 2}

I went to the war. I don't know if that precise sequence of events actually happened in the life of Tim O'Brien, the soldier/writer, but the sequence rings true to me. I remember well that " hard squeezing pressure in (my) chest, " and I didn't even go! Like O'Brien, my friends who went to Vietnam, most of them anyway, went because they couldn't tolerate the shame of the alternatives. Not to go would have been a violation of identityimpossible. As for me, I know I would not have been able to face my father, or my 
mentors who had fought the Nazi menace in WWII, had I chosen to go to jail or to Canada (COCA).

1 Is there any difference in meaning of would have been between the first passage and the second? What does would have been mean in these passages?

2 If you could change one of these underlined expressions to conditionals with if, which one is more appropriate? And how would you change it?

3 Here are some sentences with would that you have seen before. Find the sentence in which would: i) is used for polite expressions; ii) denotes inferences about the past; or iii) has negative implications (contrary to fact). How many are not used for these purposes?

a. It was half past five. Dad would have finished work.

b. To grasp or squeeze would have sent the slippery trout shooting back into the pool.

c. Would it be okay for you to come visit my office to discuss about my business proposal tomorrow?

d. In every evening of my elementary school years, some would bring basketballs to shoot hoops, while others would simply lie on the grass and take a long look at the blue sky above.

e. A single mishandling of a nuclear arsenal during the Cold War would have led to a worldwide catastrophe.

f. Come on, the package would have already arrived hours ago. 
g. We told the teacher that we definitely would still work hard even if she left the classroom.

The two features given in the task seemingly look identical, but they represent two distinctive functions, that is, the former indicates unreal situation, denoting negative-truth commitment (accordingly, which can be converted to if-clauses), while the latter is used for expressing uncertainty or tentativeness on the facticity of past events. In the third question, each example sentence corresponds to the different use of would-clause as provided in the direction. 


\title{
Appendix B Supplementary Activity 2: Dictogloss
}

\author{
Guidelines.
}

- Group students into pairs or small groups.

- Select a passage from real language texts that embeds a particular grammatical form to be emphasized (modify it if necessary).

- Review difficult or possibly unknown vocabulary that appears in the dictogloss.

- Read the dictogloss script through once at a normal speed, asking students to listen carefully.

- $\quad$ Read the dictogloss script a second time, and encourage students to jot down notes.

- Have pairs of students work together for approximately 20-25 minutes to reconstruct the text from their shared resources.

After students finish making their own versions in groups or pairs, they are allowed to read the original text so that their reconstructions can be compared with the original texts. Students will be able to notice the visually enhanced target features in the original text, which could help to discern the differences between their interlanguage form and the targeted form. Also, teachers may give explicit instruction to the students based on their level of understanding. During this collaborative work, students can focus on meaning as well as the forms by exchanging meaningful information about the target language features within their groups.

Script (read by the teacher)

After two days, without pumping, New York's subways would impassably flood. 
After one year, animals would begin to return to nuclear reactor sites, which would have all melted down by then.

After three years, with no heat, pipes in temperate or colder zones would burst all over towns.

After 100 years, with no ivory trade, the number of elephants would increase by twenty times.

After 300 years, New York's bridges would fall, and dams worldwide would have collapsed.

After 100,000 years, carbon dioxide would be back to pre-human levels.

After 10 million years, bronze sculpture would still be recognizable.

After 5 billion years, the Earth would burn up as the dying sun enlarges and consumes the inner planets.

Even without us, human radio and television broadcasts would still travel outward forever into the future.

Student handout version of the dictogloss on the next page 


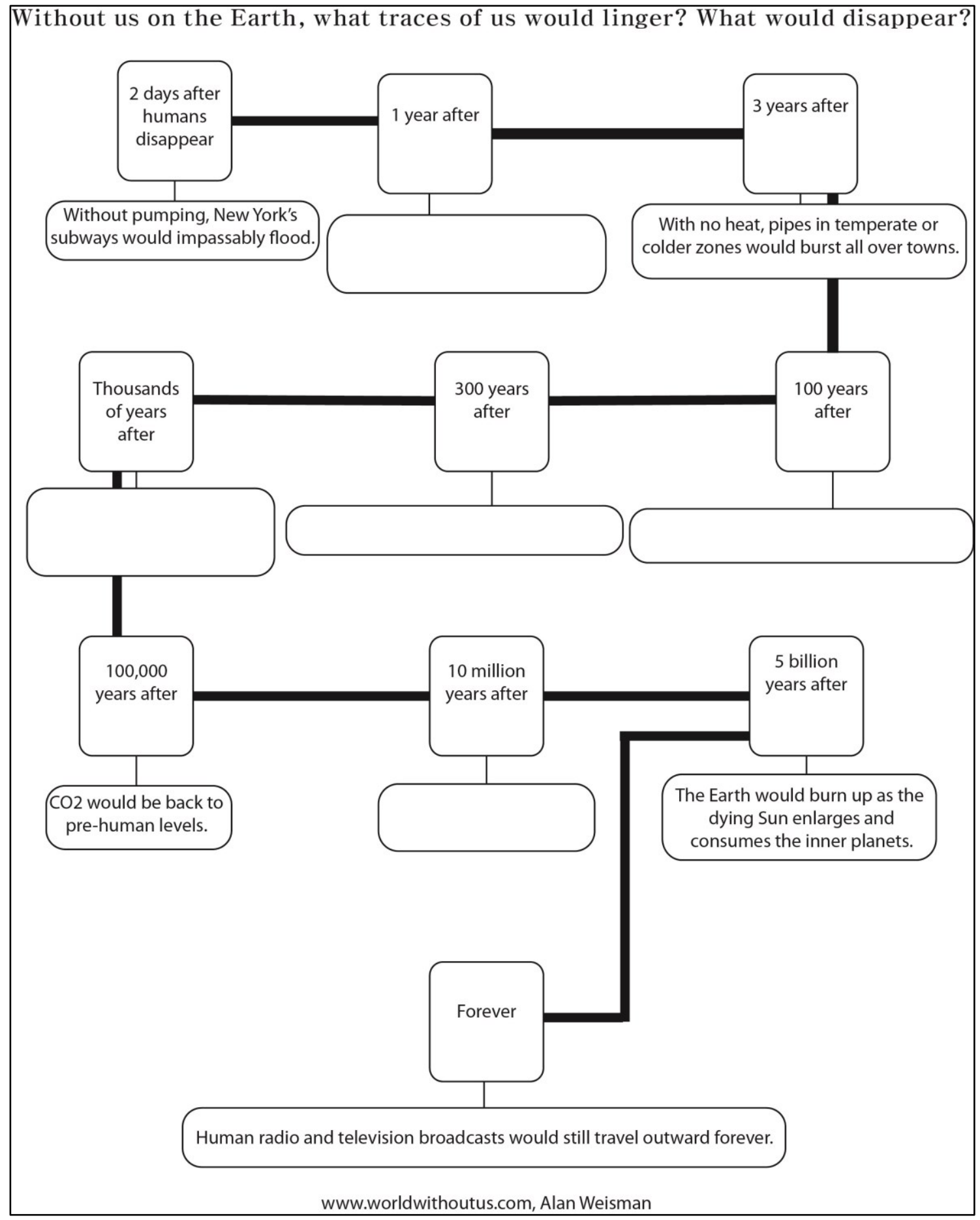

Original version of the dictogloss on the next page 


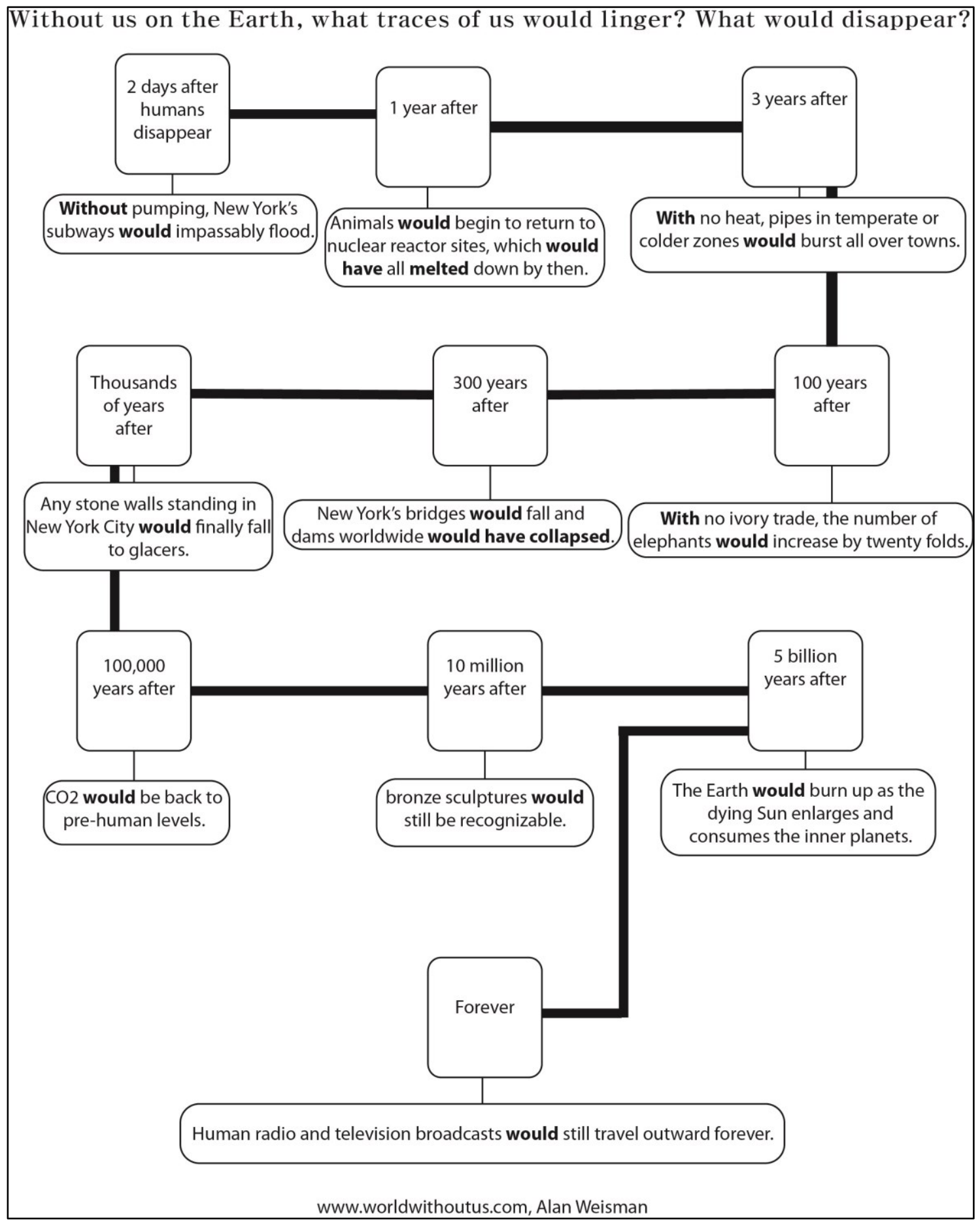

